\title{
Research Article \\ Optimal Reconfiguration Control of the Yaw Stability of the Tractor-Semitrailer Vehicle
}

\author{
Xiujian Yang \\ Faculty of Transportation Engineering, Kunming University of Science and Technology, \\ Kunming 650500, China \\ Correspondence should be addressed to Xiujian Yang, yangxj@yahoo.cn
}

Received 24 April 2012; Accepted 15 August 2012

Academic Editor: Soohee Han

Copyright (C 2012 Xiujian Yang. This is an open access article distributed under the Creative Commons Attribution License, which permits unrestricted use, distribution, and reproduction in any medium, provided the original work is properly cited.

\begin{abstract}
An optimal reconfiguration control scheme based on control allocation (CA) is proposed to stabilize the yaw dynamics of the tractor-semitrailer vehicle. The proposed control scheme is a twolevel structure consisting of an upper level of sliding mode yaw moment controller (SMYC) and a lower optimal brake force distributor (BFD). The upper SMYC is designed to follow the tractor yaw rate and the combination of the hitch angle and trailer slip angle and outputs the corrective yaw moment, respectively, for the tractor and the trailer. The optimal brake force allocation and reconfigurable control problem is transformed to a problem of error minimization and control minimization combination formulated by constrained weighted least squares (CWLS) optimization and further solved with active set (AS) algorithm. Simulation results reveal that the CA technique-based optimal reconfigurable control is rather effective for the tractor-semitrailer vehicle to enhance the yaw stability performance and the reliability in case of actuator failure thanks to the multiple-axle structure enriching the alternatives of possible actuator combinations in CA optimization.
\end{abstract}

\section{Introduction}

Tractor-semitrailer vehicle which is the combination of a tractor and a semitrailer through the hitch point presents particular handling and stability properties compared with the passenger cars. In critical driving situations, a tractor-trailer combination may experience different forms of lateral instability such as jackknife, trailer swing, and trailer oscillation $[1,2]$. In emergency situations, it is difficult for a general driver to handle the tractorsemitrailer vehicle as he recognizes the vehicle falling into instability. Fortunately, similar to the passenger cars, the stability of a tractor-trailer combination can also be obviously improved by active control approach. In recent years, there is increasing interest by both the industry and academia in having electronic stability control (ESC) systems developed for and implemented in the heavy vehicles [3-5]. The conventional ESC systems both for the passenger cars and the commercial vehicles are mainly based on the concept of direct yaw 
moment control (DYC) which is generally realized by single-wheel braking [5-9]. However, this method cannot ensure the reliability or the safety especially in the situations such as the actuator failure, and low friction adhesion of the brake actuator.

In fact, for a typical ESC system, controlled states are typically lateral velocity and yaw motion, while the actuation could potentially include individual wheel driving/braking, comprising a redundantly actuated system especially for the commercial heavy vehicles which are generally with multiple axles and wheels [10]. Coordinating all the available brake actuators to expand the operational envelope and thereby improve the reliability refers to the problem of control allocation (CA) [10], which has been widely used in the control of aircraft and marine vessels having become more and more popular in vehicle dynamics control recently [10-14]. A CA scheme with the quadratic programming algorithm and a linear quadratic regulator is proposed by [13] to distribute the control effort among the front and rear brake torque differences and steering angle to track a desired yaw rate and minimize the sideslip. Wang and Longoria [10] proposed a coordinated reconfigurable vehicle dynamics control system achieved by high-level control of generalized forces/moment, distributed to the slip and slip angle of each tyre based on the fixed-point (FP) CA method. Tagesson et al. [14] tried to apply the CA method to the yaw stability control of a type of heavy truck with one front axle and two rear axles by coordinating the brake actions of the six wheels. Though CA method has been used in the stability control of passenger cars for some time, very little reports on the heavy vehicle especially the tractor-trailer combination can be found. Different from the single-body vehicles such as passenger cars and three-axle heavy trucks, it is rather complex to implement CA technique to the tractor-semitrailer vehicle due to the particular double-body structure. In this work, optimal reconfiguration control of the yaw stability of the tractor-semitrailer vehicle based on CA technique is studied by optimizing and distributing the brake forces of the tractor and trailer wheels in real time.

The rest of the paper is organized as follows: in Section 2, a nonlinear tractor-semitrailer combination vehicle model is developed to perform the control scheme validation by simulations. The proposed control scheme is presented in Section 3 with the upper level sliding mode yaw moment controller (SMYC) and the lower level constrained weighted least squares (CWLS) based brake force distributor (BFD) designed in this section. Simulations are conducted in Section 4 to evaluate the proposed control scheme by a single lane change maneuver, followed by the conclusions given in Section 5 .

\section{Nonlinear Vehicle Model}

A typical five-axle tractor-semitrailer vehicle is considered in this study with the nonlinear schematic model illustrated by Figure 1. A 14-degree-of-freedom (14-DOF) vehicle model is constructed in this section involving the body planar motion, body roll motion, suspension and tyre forces, and wheel rotational dynamics.

\subsection{Body Motion Models}

Body planar motions for the tractor and the trailer are, respectively, described. In the modeling, the tandem axle is simplified to one single axle. For the tractor, the longitudinal, lateral, yaw, and roll dynamics are, respectively, given by (2.1)-(2.4) as

$$
m_{1}\left(\dot{v}_{x 1}-\gamma_{1} v_{y 1}\right)=\left(F_{x 1}+F_{x 2}\right) \cos \delta_{f}+F_{x 3}+F_{x 4}-\left(F_{y 1}+F_{y 2}\right) \sin \delta_{f}+F_{h x}
$$




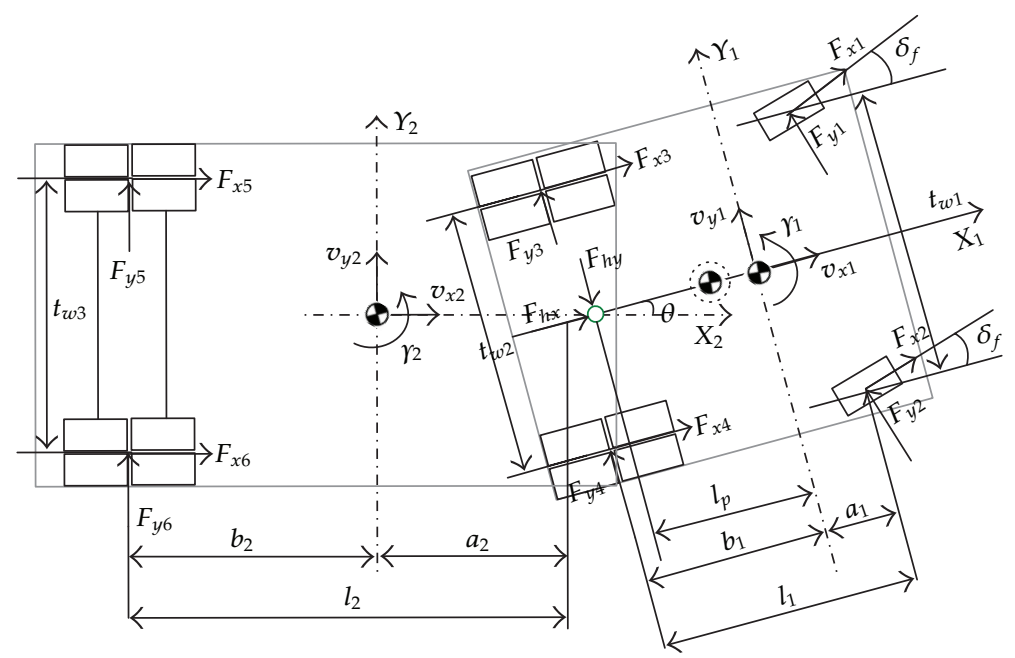

(a)

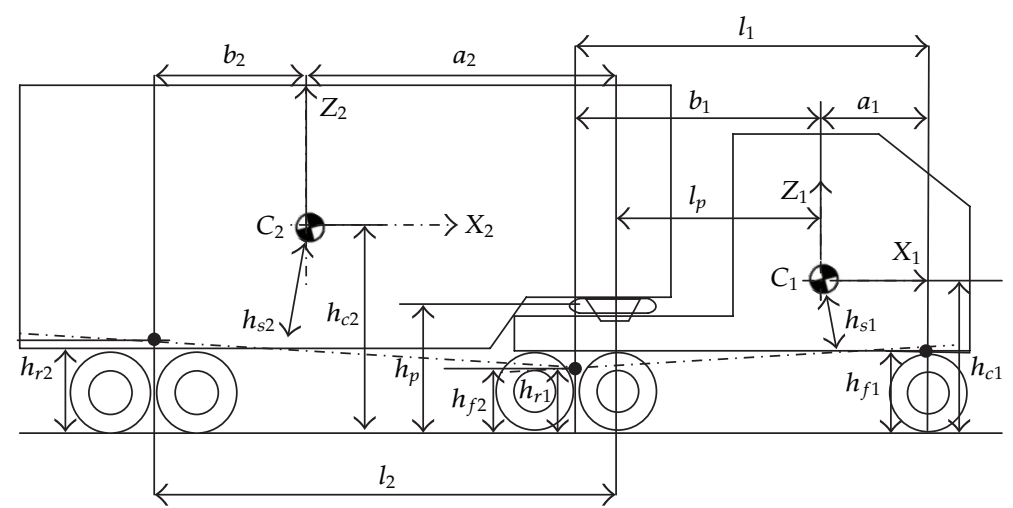

(b)

Figure 1: Nonlinear tractor-semitrailer vehicle schematic model. (a) $X-Y$ plane; (b) Z-X plane.

$$
\begin{aligned}
& m_{1}\left(\dot{v}_{y 1}+\gamma_{1} v_{x 1}\right)+m_{1 s} h_{s 1} \ddot{\phi}_{1}=\left(F_{y 1}+F_{y 2}\right) \cos \delta_{f}+F_{y 3}+F_{y 4}+\left(F_{x 1}+F_{x 2}\right) \sin \delta_{f}-F_{h y}, \\
& I_{z 1} \dot{\gamma}_{1}=\left(\left(F_{y 1}-F_{y 2}\right) \sin \delta_{f}+\left(F_{x 2}-F_{x 1}\right) \cos \delta_{f}\right) \frac{t_{w 1}}{2}-\left(F_{y 3}+F_{y 4}\right) b_{1}+\left(F_{x 4}-F_{x 3}\right) \frac{t_{w 2}}{2} \\
&+\left(\left(F_{y 1}+F_{y 2}\right) \cos \delta_{f}+\left(F_{x 1}+F_{x 2}\right) \sin \delta_{f}\right) a_{1}+F_{h y} l_{p}, \\
& I_{x 1} \ddot{\phi}_{1}+m_{1 s}\left(\dot{v}_{y 1}+\gamma_{1} v_{x 1}\right) h_{s 1}= m_{1 s} g h_{s 1} \sin \phi_{1}+\left(F_{z 2}-F_{z 1}\right) \frac{t_{w 1}}{2}+\left(F_{z 4}-F_{z 3}\right) \frac{t_{w 2}}{2} \\
&-\left(F_{y 1}+F_{y 2}\right) h_{f 1} \cos \delta_{f}-\left(F_{y 3}+F_{y 4}\right) h_{r 1}-F_{h y}\left(h_{p}-h_{r 1}\right)+M_{h t},
\end{aligned}
$$

where $m_{1}$ and $m_{1 s}$ denote the total mass and the sprung mass of the tractor; $I_{z 1}$ and $I_{x 1}$ the yaw moment of inertia and roll moment of inertia of the tractor; $a_{1}, b_{1}$, and $l_{p}$, respectively, the distance from the centre of mass $(\mathrm{CM})$ of the tractor to its front, rear axle, and the hitch point; $t_{w 1}, t_{w 2}$ the track width of tractor front axle and rear axle; $h_{f 1}$ and $h_{r 1}$ the height of 
front, rear roll centre of the tractor; $h_{s 1}$ the distance from the tractor CM to its roll axis; $h_{p}$ the height of the hitch point; $\gamma_{1}, \phi_{1}, v_{x 1}$, and $v_{y 1}$, respectively, the yaw rate, roll angle, longitudinal velocity and lateral velocity of the tractor; $F_{x i}, F_{y i}$, and $F_{z i}(i=1 \sim 4)$, respectively, the longitudinal, lateral, and normal force of the tractor wheels; $F_{h x}$, and $F_{h y}$ the longitudinal and lateral interaction force between the tractor and the trailer; $M_{h t}$ the coupling roll moment between the tractor and the trailer.

The equations of longitudinal, lateral, yaw, and roll motions of the trailer can, respectively, be expressed by (2.5)-(2.8) as

$$
\begin{gathered}
m_{2}\left(\dot{v}_{x 2}-\gamma_{2} v_{y 2}\right)=F_{x 5}+F_{x 6}-F_{h x} \cos \theta+F_{h y} \sin \theta, \\
m_{2}\left(\dot{v}_{y 2}+\gamma_{2} v_{x 2}\right)+m_{2 s} h_{s 2} \ddot{\phi}_{2}=F_{y 5}+F_{y 6}+F_{h y} \cos \theta-F_{h x} \sin \theta, \\
I_{z 2} \dot{\gamma}_{2}=\left(F_{h y} \cos \theta-F_{h x} \sin \theta\right) a_{2}-\left(F_{y 5}+F_{y 6}\right) b_{2}+\left(F_{x 6}-F_{x 5}\right) \frac{t_{w 3}}{2}, \\
I_{x 2} \ddot{\phi}_{2}+m_{2 s}\left(\dot{v}_{y 2}+\gamma_{2} v_{x 2}\right) h_{s 2}=\left(F_{z 6}-F_{z 5}\right) \frac{t_{w 3}}{2}+m_{2 s} g h_{s 2} \sin \phi_{2}+F_{h y}\left(h_{p}-h_{f 2}\right) \cos \theta \\
-\left(F_{y 5}+F_{y 6}\right) h_{r 2}-M_{h t},
\end{gathered}
$$

where $m_{2}$ and $m_{2 s}$ denote the total mass and sprung mass of the trailer; $I_{z 2}$ and $I_{x 2}$ the yaw moment of inertia and roll moment of inertia of the trailer; $a_{2}$, and $b_{2}$ the distance from the trailer CM to the hitch point and the rear axle of the trailer; $t_{w 3}$ the track width of the trailer axle; $h_{f 2}$ and $h_{r 2}$ the front and rear roll centre height of the trailer; $h_{s 2}$ the distance from the trailer CM to its roll axis; $\gamma_{2}, \phi_{2}, v_{x 2}$, and $v_{y 2}$, respectively, the yaw rate, roll angle, longitudinal velocity, and lateral velocity of the trailer; $\theta$ the hitch angle between the tractor and the trailer; $F_{x i}, F_{y i}$, and $F_{z i}(i=5,6)$, respectively, the longitudinal, lateral, and normal force of the trailer wheels.

The couplings exist in the longitudinal, lateral, yaw, and roll motions between the tractor and the trailer which can, respectively, be described by (2.9) as

$$
\begin{gathered}
v_{x 2}=v_{x 1} \cos \theta, \\
v_{y 2}=\left(v_{y 1}-l_{p} \gamma_{1}\right) \cos \theta-a_{2} \gamma_{2}-v_{x 1} \sin \theta, \\
\gamma_{2}=\gamma_{1}+\dot{\theta} \\
M_{h t}=K_{h t}\left(\phi_{2}-\phi_{1} \cos \theta\right),
\end{gathered}
$$

where $K_{h t}$ is the coupling roll stiffness between the tractor and the trailer.

\subsection{Suspension and Tyre Models}

Suspension model is built to predict the lateral load transfer when cornering which affects the tyre normal force. In heavy vehicles, leaf spring is usually used and the suspension 
force which is nonlinear with the deformation of the leaf spring can be calculated as [15] follows:

$$
\Delta F_{z i}^{\mathrm{lat}}= \begin{cases}K_{s 11} e_{i}+K_{s 12} e_{i}^{5}+D_{s 1} \dot{e}_{i,} & i=1,2 \\ K_{s 21} e_{i}+K_{s 22} e_{i}^{5}+D_{s 2} \dot{e}_{i,} & i=3,4 \\ K_{s 31} e_{i}+K_{s 32} e_{i}^{5}+D_{s 3} \dot{e}_{i,} & i=5,6\end{cases}
$$

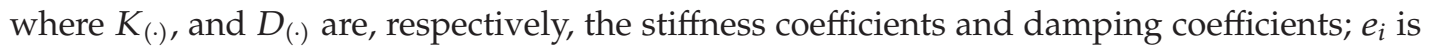
the deformation of the $i$ th suspension which can be formulated as

$$
\begin{array}{cc}
e_{1}=\frac{t_{w 1}}{2} \phi_{1}, \quad e_{2}=-\frac{t_{w 1}}{2} \phi_{1}, & e_{3}=\frac{t_{w 2}}{2} \phi_{1}, \quad e_{4}=-\frac{t_{w 2}}{2} \phi_{1}, \\
e_{5}=\left(\frac{t_{w 3}}{2} \phi_{2}\right) \cos \theta+l_{2} \phi_{2} \sin \theta, & e_{6}=-\left(\frac{t_{w 3}}{2} \phi_{2}\right) \cos \theta+l_{2} \phi_{2} \sin \theta .
\end{array}
$$

In order to capture the actual property of the tyre force in critical situations, nonlinear trye mode is introduced. The tyre normal load which relates the body motions to the tyre forces should be specially considered in the tyre force modeling. The tyre normal load for each wheel is, respectively, formulated as

$$
\begin{gathered}
F_{z 1}=\frac{m_{1} g b_{1}}{2 l_{1}}+\frac{m_{2} g b_{2}\left(b_{1}-l_{p}\right)}{2 l_{1} l_{2}}+\frac{1}{2} F_{1}^{\text {lon }}+\Delta F_{z 1}^{\text {lat }}, \\
F_{z 2}=\frac{m_{1} g b_{1}}{2 l_{1}}+\frac{m_{2} g b_{2}\left(b_{1}-l_{p}\right)}{2 l_{1} l_{2}}+\frac{1}{2} F_{1}^{\text {lon }}+\Delta F_{z 2}^{\text {lat }}, \\
F_{z 3}=\frac{m_{1} g a_{1}}{2 l_{1}}+\frac{m_{2} g b_{2}\left(a_{1}+l_{p}\right)}{2 l_{1} l_{2}}+\frac{1}{2} F_{2}^{\text {lon }}+\Delta F_{z 3}^{\text {lat }}, \\
F_{z 4}=\frac{m_{1} g a_{1}}{2 l_{1}}+\frac{m_{2} g b_{2}\left(a_{1}+l_{p}\right)}{2 l_{1} l_{2}}+\frac{1}{2} F_{2}^{\text {lon }}+\Delta F_{z 4}^{\text {lat }}, \\
F_{z 5}=\frac{m_{2} g a_{2}}{2 l_{2}}+\frac{m_{2} a_{x 2} h_{c 2}}{2 l_{2}}+\Delta F_{z 5}^{\text {lat }}, \\
F_{z 6}=\frac{m_{2} g a_{2}}{2 l_{2}}+\frac{m_{2} a_{x 2} h_{c 2}}{2 l_{2}}+\Delta F_{z 6}^{\text {lat },}
\end{gathered}
$$

with

$$
\begin{gathered}
F_{1}^{\text {lon }}=-\frac{m_{1} a_{x 1} h_{c 1}}{l_{1}}-\frac{m_{2} a_{x 2} h_{c 2}\left(b_{1}-l_{p}\right)}{l_{1} l_{2}}, \\
F_{2}^{\text {lon }}=\frac{m_{1} a_{x 1} h_{c 1}}{l_{1}}-\frac{m_{2} a_{x 2} h_{c 2}\left(b_{1}-l_{p}\right)}{l_{1} l_{2}} .
\end{gathered}
$$


Nonlinear Dugoff model [16] is used here which can well characterize the actual tyre force in critical situations. For the $i$ th wheel, the longitudinal (driving/braking) tyre force can be formulated as

$$
\begin{gathered}
F_{x i}=\frac{C_{x i} \lambda_{i}}{1-\lambda_{i}} f\left(S_{i}\right), \quad i=1,2 \ldots 6, \\
F_{y i}=\frac{C_{y i} \tan \alpha_{i}}{1-\lambda_{i}} f\left(S_{i}\right), \quad i=1,2 \ldots 6,
\end{gathered}
$$

with

$$
\begin{gathered}
S_{i}=\frac{\mu F_{z i}\left(1-\varepsilon_{r} v_{x w i} \sqrt{\lambda_{i}^{2}+\tan ^{2} \alpha_{i}}\right)}{2 \sqrt{C_{x i}^{2} \lambda_{i}^{2}+C_{y i}^{2} \tan ^{2} \alpha_{i}}}\left(1-\lambda_{i}\right), \\
f\left(S_{i}\right)= \begin{cases}1, & S_{i}>1 \\
S_{i}\left(2-S_{i}\right), & S_{i}<1,\end{cases}
\end{gathered}
$$

where $C_{x i}$ and $C_{y i}$ are, respectively, the tyre longitudinal and lateral stiffness and it is assumed that the tyres on the same axle are with the same stiffness. $\alpha_{i}$ and $\lambda_{i}$ are the tyre side slip angle and longitudinal slip ratio which can be derived from the vehicle physical geometry and vehicle states and will not be given here in detail any more for the space limit.

For the tyre $i$ with the active brake torque $T_{b i}$, the wheel rotational dynamics can be formulated by

$$
I_{w i} \dot{\omega}_{w i}=-T_{b i}-R_{w i} F_{x i}, \quad i=1,2 \ldots 6,
$$

where $R_{w i}$ is the wheel rolling radius, $I_{w i}$ the rotary moment of inertia, $\omega_{w i}$ the wheel angular velocity, and $T_{b i}$ the wheel brake torque of the $i$ th wheel.

\section{Reconfigurable Control System Design}

The reconfigurable control system as a two-level structure consists of two primary parts which are the upper level SMYC and the lower level BFD. In addition, state observer used to estimate vehicle states such as slip angle, hitch angle, and hitch angular rate and the brake force limit estimator supplying the upper bound of brake forces to the CWLS optimization as the supplementary modules are also included. The overall structure of the configurable control system is presented in Figure 2. As shown by the figure, $\Delta \mathbf{M}=\left[\begin{array}{ll}\Delta M_{1} & \Delta M_{2}\end{array}\right]^{T}$ is the corrective yaw moment from the upper level SMYC for the tractor and the trailer and $\mathbf{T}_{b}=\left[\begin{array}{llll}T_{b 1} & T_{b 2} & \cdots & T_{b 6}\end{array}\right]^{T}$ is the reconfigured brake torque from the lower level BFD for all wheels. 


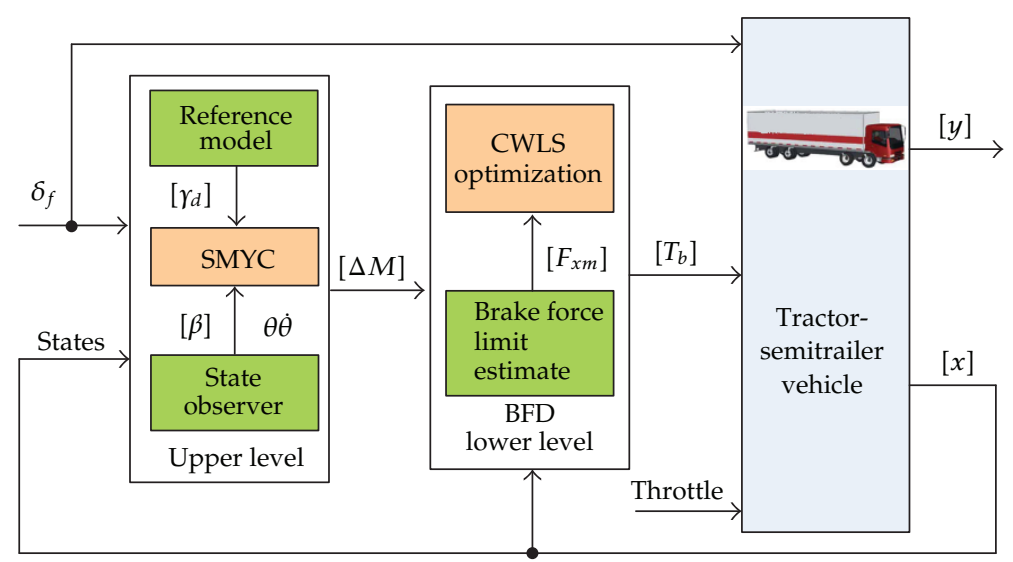

Figure 2: Overall structure of the reconfigurable control system.

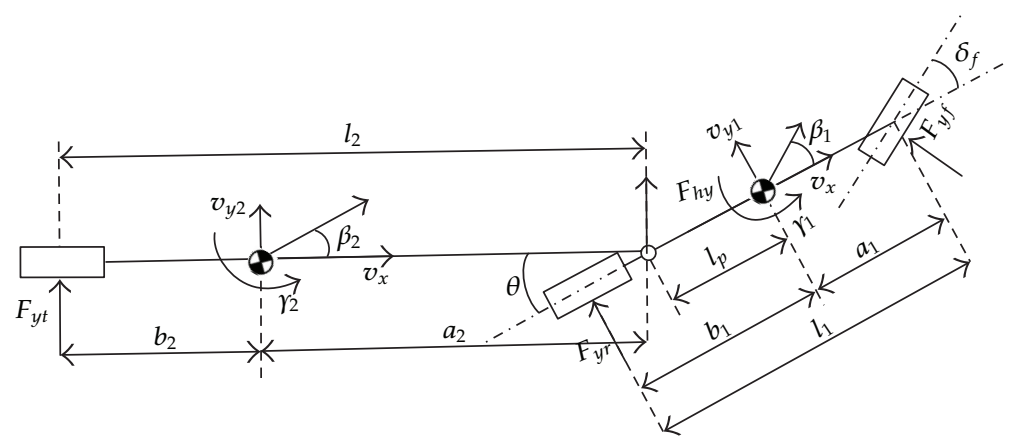

Figure 3: 4DOF single-track tractor-trailer schematic model.

\subsection{Upper Level SMYC Design}

\subsubsection{Reference Response}

Model-following technique which is often used in vehicle stability control system, that is, the actual vehicle responses follow the reference or the desired responses produced by an on board model $[9,17,18]$, is employed here. The on board model used to produce the reference response is derived from a linear single-track 4-DOF tractor-trailer model as shown in Figure 3 and the corresponding motion equations can be referred in detail to $[2,19]$.

The reference response of the tractor yaw rate in steady-state with the front wheel steer input $\delta_{f}$ at the speed of $v_{x}$ is given by

$$
\bar{\gamma}_{1 d}=\frac{v_{x} / l_{1}}{1+K_{s} v_{x}^{2}} \delta_{f}
$$

with

$$
K_{s}=\frac{b_{1} l_{2} m_{1}+\left(b_{1}-l_{p}\right) b_{2} m_{2}}{l_{1}^{2} l_{2} C_{y f}}-\frac{a_{1} l_{2} m_{1}+\left(a_{1}+l_{p}\right) b_{2} m_{2}}{l_{1}^{2} l_{2} C_{y r}},
$$


where $C_{y f}$, and $C_{y r}$ are, respectively, the linear cornering stiffness of the tractor front and rear axle in the 4-DOF single track model. In fact, the yaw rate reference response (3.1) is restricted by the tyre adhesion limit, that is,

$$
\left|\bar{\gamma}_{1 d}\right| v_{x} \leq \mu g
$$

So the dynamic reference response of the tractor yaw rate may be reasonably formulated as

$$
\gamma_{1 d}= \begin{cases}\bar{\gamma}_{1 d}, & \left|\bar{\gamma}_{1 d}\right| v_{x}<\mu g \\ \frac{\mu g}{v_{x}}, & \left|\bar{\gamma}_{1 d}\right| v_{x} \geq \mu g\end{cases}
$$

Similarly, the reference response of the hitch angle can be obtained as well from the linear 4-DOF model as

$$
\theta_{d}=\frac{p_{1}+\left(p_{2}+p_{3}\right) v_{x}^{2}}{1+K_{s} v_{x}^{2}} \delta_{f}
$$

with

$$
p_{1}=-\frac{l_{p}-b_{1}+l_{2}}{l_{1}}, \quad p_{2}=\frac{a_{2} m_{2}}{l_{1} l_{2} C_{y t}}, \quad p_{3}=-\frac{a_{1} l_{2} m_{1}+\left(a_{1}+l_{p}\right) b_{2} m_{2}}{l_{1}^{2} l_{2} C_{y r}},
$$

here $C_{y_{t}}$ is the linear cornering stiffness of the trailer axle in the 4-DOF single track model. Then the reference response of the hitch angular rate can thereby be derived as follows:

$$
\dot{\theta}_{d}=\frac{\partial \theta_{d}}{\partial v_{x}} \frac{d v_{x}}{d t}=\frac{2\left(K_{u 1} \Delta l-K_{u 2} l_{1}\right) v_{x} \dot{v}_{x}}{\left(l_{1}+K_{u 1} v_{x}^{2}\right)^{2}} \delta_{f}
$$

with

$$
\begin{aligned}
K_{u 1} & =\frac{b_{1} l_{2} m_{1}+\left(b_{1}-l_{p}\right) b_{2} m_{2}}{l_{1} l_{2} C_{y f}}-\frac{a_{1} l_{2} m_{1}+\left(a_{1}+l_{p}\right) b_{2} m_{2}}{l_{1} l_{2} C_{y r}}, \\
K_{u 2} & =\frac{a_{1} l_{2} m_{1}+\left(a_{1}+l_{p}\right) b_{2} m_{2}}{l_{1} l_{2} C_{y r}}-\frac{a_{2} m_{2}}{l_{2} C_{y t}}, \\
\Delta l & =l_{p}-b_{1}+l_{2} .
\end{aligned}
$$

In vehicle stability control system design based on model following method, the reference slip angle may be derived from the linear single-track model or directly set zero by simplicity which is also viable and can even obtain satisfying control performance $[8,9$, $17,18]$. A zero reference slip angle for the trailer is employed here to be followed in the controller design, that is, $\beta_{2 d}=0$. 


\subsubsection{SMYC Design}

The yaw dynamics of the tractor and the trailer are individually stabilized by a corrective yaw moment to, respectively, follow the reference responses of the tractor yaw rate and the combination of the hitch angular rate and trailer slip angle. Sliding mode control method which is robust against parametric uncertainties is employed to complete the control objective. Define the system states $\mathbf{x}=\left[\begin{array}{llll}v_{y 1} & \gamma_{1} & \theta & \dot{\theta}\end{array}\right]^{T}=\left[\begin{array}{llll}x_{1} & x_{2} & x_{3} & x_{4}\end{array}\right]^{T}$ and the 4-DOF single-track model equations with the active corrective yaw moment $\Delta \mathbf{M}=\left[\begin{array}{ll}\Delta M_{1} & \Delta M_{2}\end{array}\right]^{T}$ can be rewritten as

$$
\dot{\mathbf{x}}=\mathbf{A} \mathbf{x}+\mathbf{B}_{1} u_{1}+\mathbf{B}_{2} \mathbf{u}_{2}
$$

with $\mathbf{A} \in R^{4 \times 4}, \mathbf{A}=\mathbf{M}^{-1} \mathbf{V}, \mathbf{B}_{1} \in R^{4 \times 1}, \mathbf{B}_{1}=\mathbf{M}^{-1} \mathbf{W}, \mathbf{B}_{2} \in R^{4 \times 2}, \mathbf{B}_{2}=\mathbf{M}^{-1} \mathbf{Y}, u_{1}=\delta_{f}$, and $\mathbf{u}_{2}=\Delta \mathbf{M}$, where

$$
\begin{aligned}
& \mathbf{M}=\left(\begin{array}{cccc}
m_{1} l_{p} & I_{z 1} & 0 & 0 \\
m_{1}+m_{2} & -m_{2}\left(l_{p}+a_{2}\right) & 0 & -m_{2} a_{2} \\
m_{1} a_{2} & I_{z 2} & 0 & I_{z 2} \\
0 & 0 & 1 & 0
\end{array}\right) \\
& \mathbf{V}=\frac{1}{v_{x}}\left(\begin{array}{cccc}
v_{11} & v_{12} & 0 & 0 \\
v_{21} & v_{22} & C_{y t} v_{x} & l_{2} C_{y t} \\
v_{31} & v_{32} & -b_{2} C_{y t} v_{x} & -b_{2} l_{2} C_{y t} \\
0 & 0 & 0 & v_{x}
\end{array}\right) \\
& v_{11}=-\left(a_{1}+l_{p}\right) C_{y f}-\left(l_{p}-b_{1}\right) C_{y r}, \quad v_{21}=-\left(C_{y f}+C_{y r}+C_{y t}\right), \\
& v_{31}=-C_{y f} a_{2}-C_{y r} a_{2}+C_{y t} b_{2}, \quad v_{12}=-a_{1}\left(a_{1}+l_{p}\right) C_{y f}-b_{1}\left(b_{1}-l_{p}\right) C_{y r}-v_{x}^{2} l_{p} m_{1}, \\
& v_{22}=-a_{1} C_{y f}+b_{1} C_{y r}+\left(l_{2}+l_{p}\right) C_{y t}-\left(m_{1}+m_{2}\right) v_{x \prime}^{2} \\
& v_{32}=-a_{1} a_{2} C_{y f}+a_{2} b_{1} C_{y r}-b_{2}\left(l_{2}+l_{p}\right) C_{y t}-m_{1} a_{2} v_{x}^{2} \\
& \mathbf{W}=\left(\begin{array}{c}
\left(a_{1}+l_{p}\right) C_{y f} \\
C_{y f} \\
a_{2} C_{y f} \\
0
\end{array}\right), \quad \mathbf{Y}=\left(\begin{array}{ll}
1 & 0 \\
0 & 0 \\
0 & 1 \\
0 & 0
\end{array}\right)
\end{aligned}
$$

Two sliding surfaces are, respectively, designed for the control of the tractor and the trailer as

$$
\begin{gathered}
s_{1}=x_{2}-x_{2 d}, \\
s_{2}=\xi_{1}\left(\beta_{2}-\beta_{2 d}\right)+\xi_{2}\left(x_{4}-x_{4 d}\right), \quad 0 \leq \xi_{1}, \xi_{2} \leq 1,
\end{gathered}
$$

with

$$
\beta_{2}=\frac{x_{1}}{v_{x}}-\frac{l_{p}}{v_{x}} x_{2}-\frac{a_{2}}{v_{x}}\left(x_{2}+x_{4}\right), \quad \beta_{2 d}=0 .
$$


Then the attractive equations can be formulated as

$$
\begin{aligned}
& \dot{s}_{1}=\dot{x}_{2}-\dot{x}_{2 d}=-\varepsilon_{11} \operatorname{sgn}\left(s_{1}\right)-\varepsilon_{12} s_{1}, \\
& \dot{s}_{2}=\xi_{1}\left(\frac{\dot{x}_{1}}{v_{x}}-\frac{l_{p}}{v_{x}} \dot{x}_{2}-\frac{a_{2}}{v_{x}}\left(\dot{x}_{2}+\dot{x}_{4}\right)\right)+\xi_{2}\left(\dot{x}_{4}-\dot{x}_{4 d}\right)=-\varepsilon_{21} \operatorname{sgn}\left(s_{2}\right)-\varepsilon_{22} s_{2},
\end{aligned}
$$

where $\varepsilon_{i j}(i, j=1,2)$ are positive, and $\operatorname{sgn}\left(s_{1,2}\right)$ is the sign function. Parameters $\xi_{1}, \xi_{2}$ in the sliding surface (3.14) are designed to regulate the control weight between the yaw dynamics and the lateral stability of the trailer. The derivatives of the reference responses of the tractor yaw rate, the hitch angular rate, and trailer slip angle are, respectively, given as follows:

$$
\begin{gathered}
\dot{x}_{2 d}=\frac{\partial x_{2 d}}{\partial v_{x}} \frac{d v_{x}}{d t}=\frac{\left(1-K_{s} v_{x}^{2}\right) \dot{v}_{x}}{\left(1+K_{s} v_{x}^{2}\right) l_{1}} \delta_{f} \\
\dot{x}_{4 d}=\frac{\partial x_{4 d}}{\partial v_{x}} \frac{d v_{x}}{d t}=\frac{2\left(K_{u 1} \Delta l-K_{u 2} l_{1}\right)\left(l_{1}-3 K_{u 1} v_{x}^{2}\right)}{\left(l_{1}+K_{u 1} v_{x}^{2}\right)^{3}} \dot{v}_{x}^{2} \delta_{f} .
\end{gathered}
$$

Attractive equations given by (3.13) and (3.14) can guarantee the deviations of state response asymptotically converge to zero. However, the positive constants $\varepsilon_{i j}$ still should be selected properly to improve the control and response quality.

Combining the 4-DOF vehicle model (3.9) and the attractive equations (3.13) and (3.14), the corrective yaw moment control law, respectively, for the tractor and the trailer can be formulated as

$$
\begin{aligned}
& \Delta M_{1}=\frac{1}{\xi_{2} v_{x}\left(m_{1}+m_{2}\right)-\xi_{1} a_{2} m_{1}} \\
& \times\left\{2\left[-\xi_{2} v_{x}\left(m_{2} a_{1}+m_{2} l_{p}+a_{1} m_{1}\right)+\xi_{1} a_{1} a_{2} m_{1}\right] F_{y f}\right. \\
& \quad+2\left[b_{1} \xi_{2} v_{x} m_{1}+\xi_{2} v_{x}\left(b_{1}-l_{p}\right) m_{2}-\xi_{1} a_{2} b_{1} m_{1}\right] F_{y r} \\
& \quad+\left[2 m_{1} l_{p}\left(\xi_{2} v_{x}-\xi_{1} a_{2}+\xi_{1} x_{4}\right)\right] F_{y t} \\
& \quad+\xi_{2} v_{x} l_{p} m_{1} m_{2}\left(-v_{x} x_{4}+a_{2} \dot{x}_{4 d}\right)+\xi_{1} v_{x} l_{p} m_{1} m_{2} a_{2}\left(x_{2}+x_{4}\right) \\
&+m_{1} I_{z 1} \xi_{1} a_{2}\left(\operatorname{sgn}\left(s_{1}\right) \varepsilon_{11}+s_{1} \varepsilon_{12}-\dot{x}_{2 d}\right) \\
& \\
&-\left(m_{1}+m_{2}\right) I_{z 1} \xi_{2} v_{x}\left(\operatorname{sgn}\left(s_{1}\right) \varepsilon_{11}+s_{1} \varepsilon_{12}-\dot{x}_{2 d}\right) \\
&-\left[\xi_{2} v_{x} m_{1} m_{2} l_{p}\left(a_{2}+l_{p}\right)\right]\left(\operatorname{sgn}\left(s_{1}\right) \varepsilon_{11}+s_{1} \varepsilon_{12}-\dot{x}_{2 d}\right) \\
&\left.+a_{2} l_{p} m_{1} m_{2} v_{x}\left(\operatorname{sgn}\left(s_{2}\right) \varepsilon_{21}-s_{2} \varepsilon_{22}\right)\right\}
\end{aligned}
$$




$$
\begin{aligned}
& \Delta M_{2}=\frac{1}{\xi_{2}} v_{x}\left(m_{1}+m_{2}\right)-\xi_{1} a_{2} m_{1} \\
& \times\left\{\left[-2\left(\xi_{1} I_{z 2}+\xi_{2} v_{x} a_{2} m_{2}\right)\right]\left(F_{y f}+F_{y r}\right)\right. \\
&+\left[2\left(-\xi_{1} a_{2} l_{2} m_{1}+\xi_{2} v_{x}\left(m_{1} l_{2}+m_{2} b_{2}-2 \xi_{1} m_{1} I_{z 2}\right)\right)\right] F_{y t} \\
&+\left[-\xi_{2} v_{x} m_{2} m_{1}\left(a_{2}^{2}+a_{2} l_{p}\right)\right]\left(\operatorname{sgn}\left(s_{1}\right) \varepsilon_{11}+s_{1} \varepsilon_{12}-\dot{x}_{1 d}\right) \\
&-I_{z 2} \xi_{2} v_{x}\left(m_{1}+m_{2}\right)\left(\operatorname{sgn}\left(s_{1}\right) \varepsilon_{11}+s_{1} \varepsilon_{12}-\dot{x}_{2 d}\right) \\
&-I_{z 2} \xi_{1} l_{p} m_{1}\left(\operatorname{sgn}\left(s_{1}\right) \varepsilon_{11}+s_{1} \varepsilon_{12}-\dot{x}_{2 d}\right) \\
&-m_{1} m_{2} v_{x} a_{2}^{2}\left(\operatorname{sgn}\left(s_{2}\right) \varepsilon_{21}+s_{2} \varepsilon_{22}-\xi_{1} x_{4}-\xi_{2} \dot{x}_{4 d}\right) \\
&-v_{x} I_{z 2}\left(m_{1}+m_{2}\right)\left(\operatorname{sgn}\left(s_{2}\right) \varepsilon_{21}+s_{2} \varepsilon_{22}-\xi_{1} x_{4}-\xi_{2} \dot{x}_{4 d}\right) \\
&+m_{1} v_{x}\left(m_{2} a_{2} \xi_{2} v_{x}+\xi_{1} I_{z 2}\right) x_{2} \\
&\left.+m_{2} v_{x}\left[\xi_{1}\left(I_{z 2}+m_{1} a_{2}^{2}\right)-\xi_{2} a_{2} v_{x} m_{1}\right]\left(x_{2}+x_{4}\right)\right\}
\end{aligned}
$$

where the tyre force in the control law are calculated from a linear tyre model with nominal tyre cornering stiffness; those are $F_{y f}=C_{y f} \alpha_{f}, F_{y r}=C_{y r} \alpha_{r}, F_{y t}=C_{y t} \alpha_{t} . \alpha_{f}, \alpha_{r}$, and $\alpha_{t}$, respectively, which are related to the side slip angle of the front, rear axle of the tractor and the trailer axle in the linear single-track model, and $C_{y f}, C_{y r}$, and $C_{y t}$ are, respectively, the corresponding cornering stiffness. Though the cornering stiffness is assumed constant, it is still feasible since sliding mode control is robust and can make the actual states track the reference responses.

In real implementation, some vehicle states such as the tractor/trailer slip angle and hitch angle/angular rate. unsuitable to be measured directly by sensors for the cost considerations can be obtained by an observer since numerous state estimation algorithms have been proposed in the literature [20,21]. For the space limit, the state observer is not presented here in detail and assuming the states can be obtained directly in simulations.

\subsection{Lower Level BFD Design}

After the upper level SMYC is designed, the following step is to develop the lower level BFD to map the corrective yaw moment $\Delta \mathbf{M}$ from the upper level to a set of physical vehicle actuator commands/brake forces. The key issue of which is how to select a set of brake forces from all possible combinations since the solution to achieve the desired control is not unique for redundantly actuated systems. The problem concerned with CA can generally be formulated as

$$
\mathbf{v}=\mathbf{B u}, \quad \mathbf{u}_{\min } \leq \mathbf{u} \leq \mathbf{u}_{\max },
$$

where $\mathbf{v}$ is the virtual control vector with $\mathbf{v}=\Delta \mathbf{M}$ in this study; $\mathbf{u}$ is the actuator effort vector corresponding to the brake force vector, that is, $\mathbf{u}=\left[F_{x 1}, F_{x_{2}}, \ldots, F_{x 6}\right]^{T} ; \mathbf{u}_{\min }$ and $\mathbf{u}_{\max }$ are 
the actuator effort limits corresponding to the brake force limits, here mainly affected by the adhesion coefficient; $\mathbf{B}$ is the control effectiveness matrix and can be further expressed as

$$
\mathbf{B}=\overline{\mathbf{B}} \kappa
$$

with $\overline{\mathbf{B}}$ denoting the input matrix, $\boldsymbol{\kappa}$ the actuator effectiveness matrix which is used to express the effectiveness level of the six wheel brake force. Define

$$
\boldsymbol{\kappa}=\operatorname{diag}\left(k_{1}, k_{2}, \ldots, k_{6}\right), \quad 0 \leq k_{i} \leq 1
$$

and for the $i$ th wheel, $k_{i}=1$ means this wheel brake actuator works in the normal control situation without any failure, $k_{i}=0$ means the actuator is completely invalid due to the actuator failure and cannot produce any brake force while $0<k_{i}<1$ means the actuator partly falls in failure and can only provide part brake force compared to the normal situation of $k_{i}=1$.

With small steer angle and hitch angle assumptions, (2.3) and (2.7) can be rewritten as

$$
\begin{gathered}
I_{z 1} \dot{\gamma}_{1}=\left(F_{y 1}+F_{y 2}\right) a_{1}-\left(F_{y 3}+F_{y 4}\right) b_{1}+\Delta M_{1}+F_{h y} l_{p}, \\
I_{z 2} \dot{\gamma}_{2}=F_{h y} a_{2}-\left(F_{y 5}+F_{y 6}\right) b_{2}+\Delta M_{2},
\end{gathered}
$$

with

$$
\Delta M_{1}=\left(F_{x 2}-F_{x 1}\right) \frac{t_{w 1}}{2}+\left(F_{x 4}-F_{x 3}\right) \frac{t_{w 2}}{2}, \quad \Delta M_{2}=\left(F_{x 6}-F_{x 5}\right) \frac{t_{w 3}}{2}
$$

Then the input matrix can be defined as

$$
\overline{\mathbf{B}}=\left(\begin{array}{cccccc}
-\frac{t_{w 1}}{2} & \frac{t_{w 1}}{2} & -\frac{t_{w 2}}{2} & \frac{t_{w 2}}{2} & 0 & 0 \\
0 & 0 & 0 & 0 & -\frac{t_{w 3}}{2} & \frac{t_{w 3}}{2}
\end{array}\right)
$$

As can be observed from (3.22), the improvements of vehicle attitude by active wheel braking for the tractor and the trailer are uncoupled with each other for the purpose of simplifying the CA problem which is not the case actually. However, it is not necessary to worry about that since the corrective yaw moments $\Delta M_{1}$ and $\Delta M_{2}$ from the upper level SMYC are coupled.

In order to solve the CA problem (3.17), the actuator limits $\mathbf{u}_{\min }$ and $\mathbf{u}_{\max }$ should be determined first. In vehicle dynamics, the brake force limit for a certain wheel is not constant but varies with the driving conditions since the longitudinal tyre force is generally affected by the road friction adhesion coefficient and tyre normal force which directly relates to the maneuver. Estimating the brake force limit accurately in real time plays a key role in enhancing the reconfigurable control performance. Obviously, the brake force is negative according to the definition given by Figure 1 . Now define the brake force limit of the $i$ th wheel as

$$
F_{x m i} \leq F_{x i} \leq 0
$$




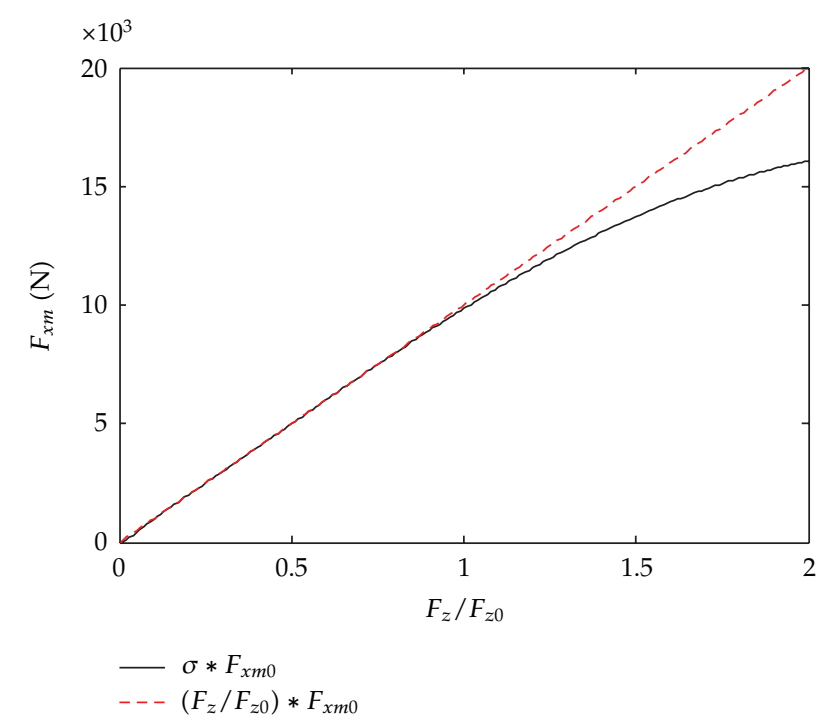

Figure 4: Influence of the tyre normal force to the brake force limit.

with

$$
F_{x m i}=\sigma_{i} F_{x 0 i},
$$

where $\sigma_{i}$ relates the longitudinal force limit to the normal force variation. According to the actual tyre force property $[16,22]$, define

$$
\sigma_{i}=\tau_{i} \sin \left[c_{1} \arctan \left(c_{2} \tau_{i}\right)+c_{3} \arctan \left(c_{4} \tau_{i}\right)\right]
$$

where $c_{1} \sim c_{4}$ are experiential constants, and $\tau_{i}$ is the ratio of the dynamic tyre normal force to the static value, that is,

$$
\tau_{i}=\frac{F_{z i}}{F_{z 0 i}}
$$

In real implementation, the dynamic tyre normal force $F_{z i}$ can be estimated according to (2.12) by the information of longitudinal and lateral accelerations which can be measured in real time. With the specified values of $c_{1}=1.3, c_{2}=20, c_{3}=-1.99$, and $c_{4}=0.3$ in this study and assuming $F_{x m 0}=10000 \mathrm{~N}$, the influence of the tyre normal force on the brake force limit is illustrated by Figure 4. As shown in the figure, the proposed estimated brake force limit which is nonlinear against the tyre normal force is consistent with the actual tyre force property.

For the CA problem formulated by (3.17), it can be understood as follows. Given a virtual control command $\mathbf{v}$, determine $\mathbf{u}$ satisfying the actuator limit $\mathbf{u}_{\min } \leq \mathbf{u} \leq \mathbf{u}_{\max }$ such that $\mathbf{v}=\mathbf{B u}$. If there exist more than one solution, take the best one. Otherwise, if there is no accurate solution, determine $\mathbf{u}$ such that $\mathbf{B u}$ approximates $\mathbf{v}$ as possible. In order to 
follow the reference responses of the on board model as well as the consideration of the brake force limits, the brake force optimization allocation is equivalent to a problem of error minimization and control minimization combination which can be formulated by CWLS optimization problem as follows:

$$
\begin{gathered}
\min \varsigma\left\|\mathbf{W}_{\mathbf{u}}\left(\mathbf{u}-\mathbf{u}_{\mathbf{d}}\right)\right\|_{2}^{2}+(1-\varsigma)\left\|\mathbf{W}_{\mathbf{v}}(\mathbf{B u}-\mathbf{v})\right\|_{2}^{2} \\
\text { s.t. } \quad \mathbf{u}_{\min } \leq \mathbf{u} \leq \mathbf{u}_{\max },
\end{gathered}
$$

where $\mathbf{u}_{\mathrm{d}}$ is the preferred control effort vector and take $\mathbf{u}_{\mathbf{d}}=0$ here to minimize the brake force effort; $\mathbf{W}_{\mathbf{u}}$ and $\mathbf{W}_{\mathbf{v}}$ are nonsingular weighting matrices with

$$
\begin{gathered}
\mathbf{W}_{\mathbf{u}}=\operatorname{diag}\left(W_{u 1}, W_{u 2}, \ldots, W_{u 6}\right), \\
\mathbf{W}_{\mathbf{v}}=\operatorname{diag}\left(W_{v 1}, W_{v 2}\right),
\end{gathered}
$$

where $s$ is the weighting factor to weight the actuator effort and control error. The brake force lower bound vector $\mathbf{u}_{\min }$ is derived from brake force limit estimation in real time by (3.24)-(3.26), that is, $\mathbf{u}_{\min }=\left[F_{x m 1}, F_{x m 2}, \ldots, F_{x m 6}\right]^{T}$. The upper bound $\mathbf{u}_{\max }$ is set zero.

Since

$$
\begin{aligned}
\varsigma\left\|\mathbf{W}_{\mathbf{u}}\left(\mathbf{u}-\mathbf{u}_{\mathbf{d}}\right)\right\|_{2}^{2}+(1-\varsigma)\left\|\mathbf{W}_{\mathbf{v}}(\mathbf{B u}-\mathbf{v})\right\|_{2}^{2} & =\left\|\left(\begin{array}{c}
\sqrt{(1-\varsigma)} \mathbf{W}_{\mathbf{v}} \mathbf{B} \\
\sqrt{\varsigma} \mathbf{W}_{\mathbf{u}}
\end{array}\right) \mathbf{u}-\left(\begin{array}{c}
\sqrt{(1-\varsigma)} \mathbf{W}_{\mathbf{v}} \mathbf{v} \\
\sqrt{\varsigma} \mathbf{W}_{\mathbf{u}} \mathbf{u}_{\mathbf{d}}
\end{array}\right)\right\|_{2}^{2} \\
& =\|\widetilde{\mathbf{B}} \mathbf{u}-\widetilde{\mathbf{v}}\|_{2^{\prime}}^{2}
\end{aligned}
$$

the CA problem (3.27) is equivalent to the optimization problem

$$
\mathbf{u}=\arg \min _{\mathbf{u}_{\min } \leq \mathbf{u} \leq \mathbf{u}_{\max }}\|\widetilde{\mathbf{B}} \mathbf{u}-\widetilde{\mathbf{v}}\|_{2^{\prime}}^{2}
$$

with

$$
\widetilde{\mathbf{B}}=\left(\begin{array}{c}
\sqrt{(1-\varsigma)} \mathbf{W}_{\mathbf{v}} \mathbf{B} \\
\sqrt{\varsigma} \mathbf{W}_{\mathbf{u}}
\end{array}\right), \quad \tilde{\mathbf{v}}=\left(\begin{array}{c}
\sqrt{(1-\varsigma)} \mathbf{W}_{\mathbf{v}} \mathbf{v} \\
\sqrt{\varsigma} \mathbf{W}_{\mathbf{u}} \mathbf{u}_{\mathbf{d}}
\end{array}\right),
$$

which can be solved with the active set (AS) algorithm [23]. This method starts at an initial guess of the solution. The elements of $\mathbf{u}$ which are on the border of the feasible set are made fixated, and other elements are left completely free. For these free elements the optimal solution is calculated.

\section{Simulation Results}

Single lane change maneuver is carried out in this section to evaluate the proposed reconfigurable control scheme based on CA technique by numerical simulations on the 14-DOF 


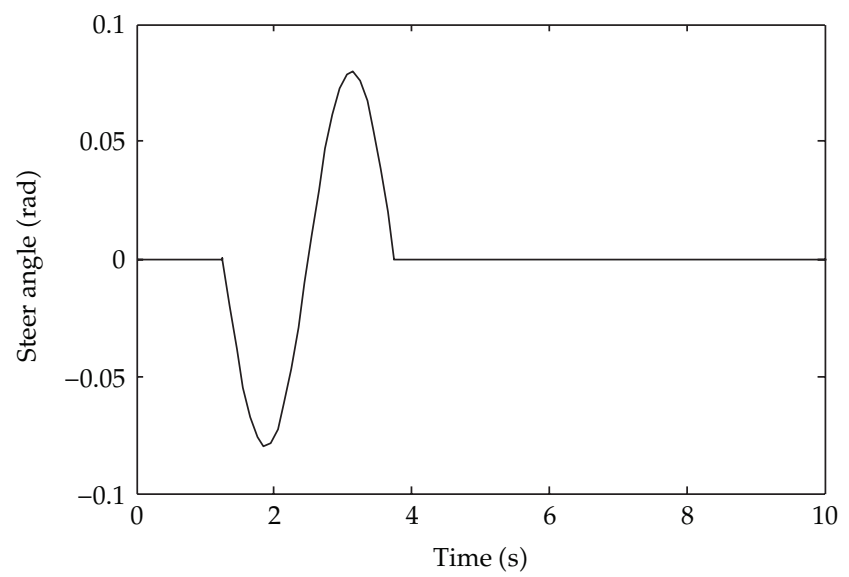

Figure 5: Front wheel steer angle.

Table 1: Vehicle parameters.

\begin{tabular}{lccccc}
\hline$m_{1}$ & $8444 \mathrm{~kg}$ & $h_{c 1}$ & $1.18 \mathrm{~m}$ & $K_{s 21}$ & $4.32 \times 10^{4} \mathrm{~N} / \mathrm{rad}$ \\
$m_{2}$ & $25000 \mathrm{~kg}$ & $h_{f 1}$ & $0.75 \mathrm{~m}$ & $K_{s 22}$ & $7.20 \times 10^{10} \mathrm{~N} / \mathrm{rad}$ \\
$m_{1 s}$ & $5820 \mathrm{~kg}$ & $h_{f 2}$ & $0.60 \mathrm{~m}$ & $K_{s 31}$ & $7.68 \times 10^{4} \mathrm{~N} / \mathrm{rad}$ \\
$m_{2 s}$ & $21640 \mathrm{~kg}$ & $h_{r 2}$ & $0.80 \mathrm{~m}$ & $K_{s 32}$ & $9.60 \times 10^{11} \mathrm{~N} / \mathrm{rad}$ \\
$I_{x 1}$ & $10347 \mathrm{~kg} \cdot \mathrm{m}^{2}$ & $t_{w 1}$ & $1.93 \mathrm{~m}$ & $C_{x 1}$ & $6.00 \times 10^{4} \mathrm{~N} / \mathrm{unit} \mathrm{slip}$ \\
$I_{x 2}$ & $58270 \mathrm{~kg} \cdot \mathrm{m}^{2}$ & $t_{w 3}$ & $1.84 \mathrm{~m}$ & $C_{y 1}$ & $3.00 \times 10^{4} \mathrm{~N} / \mathrm{rad}$ \\
$I_{z 1}$ & $65734.6 \mathrm{~kg} \cdot \mathrm{m}^{2}$ & $h_{\mathrm{s} 2}$ & $1.40 \mathrm{~m}$ & $C_{x 2}$ & $1.30 \times 10^{5} \mathrm{~N} / \mathrm{unit} \mathrm{slip}$ \\
$I_{z 2}$ & $560000 \mathrm{~kg} \cdot \mathrm{m}^{2}$ & $h_{c 2}$ & $2.03 \mathrm{~m}$ & $C_{y 2}$ & $9.00 \times 10^{4} \mathrm{~N} / \mathrm{rad}$ \\
$a_{1}$ & $2.12 \mathrm{~m}$ & $h_{r 1}$ & $0.82 \mathrm{~m}$ & $C_{x 3}$ & $1.70 \times 10^{5} \mathrm{~N} / \mathrm{unit} \mathrm{slip}$ \\
$l_{1}$ & $4.81 \mathrm{~m}$ & $h_{p}$ & $1.27 \mathrm{~m}$ & $C_{y 3}$ & $1.20 \times 10^{5} \mathrm{~N} / \mathrm{rad}$ \\
$l_{p}$ & $2.60 \mathrm{~m}$ & $K_{h t}$ & $6.90 \times 10^{6} \mathrm{Nm} / \mathrm{rad}$ & $R_{w 1 \sim 3}$ & $0.52 \mathrm{~m}$ \\
$l_{2}$ & $11.82 \mathrm{~m}$ & $K_{s 11}$ & $1.60 \times 10^{4} \mathrm{~N} / \mathrm{rad}$ & $I_{w 1}$ & $40.8 \mathrm{~kg} \cdot \mathrm{m}^{2}$ \\
$t_{w 2}$ & $1.84 \mathrm{~m}$ & $K_{s 12}$ & $2.40 \times 10^{10} \mathrm{~N} / \mathrm{rad}$ & $I_{w 2,3}$ & $130 \mathrm{~kg} \cdot \mathrm{m}^{2}$ \\
$h_{s 1}$ & $0.40 \mathrm{~m}$ & $D_{s 1 \sim 3}$ & $8.50 \times 10^{3} \mathrm{~N} / \mathrm{rad} \cdot \mathrm{s}^{-1}$ & $g$ & $9.81 \mathrm{~m} / \mathrm{s}^{2}$ \\
\hline
\end{tabular}

nonlinear vehicle model constructed in Section 2. Three cases which are normal control, actuator failure control, and uncontrolled are considered in the simulations. The normal control relates to the case where the wheel brake actuator works well without any failure; in the actuator failure control case the brake actuator partly falls in failure and can only provide part brake force compared to the normal control case while the uncontrolled case means without active control applied to the vehicle to correct the yaw dynamics. One cycle sinusoid signal with the amplitude of $0.08 \mathrm{rad}$ is used for the front wheel steer angle for the single lane change maneuver illustrated by Figure 5. Vehicle parameters in the simulation are given by Table 1.

The normal case and the failure case are realized through setting the actuator effectiveness matrix equation (3.19). For the normal control case, set $\boldsymbol{\kappa}=\operatorname{diag}\left(\begin{array}{llllll}1 & 1 & 1 & 1 & 1 & 1\end{array}\right)$ and set $\boldsymbol{\kappa}=\operatorname{diag}\left(\begin{array}{llllll}0.01 & 0.01 & 0.005 & 0.005 & 0 & 0\end{array}\right)$ for the failure case which means that the front and rear axle brake actuators are partly failed while the trailer axle brake actuators are completely failed. Setting the weighting matrices $\mathbf{W}_{\mathbf{u}}=\operatorname{diag}\left(\begin{array}{llllll}1.0 & 1.0 & 1.5 & 1.5 & 1.0 & 1.0\end{array}\right), \mathbf{W}_{\mathbf{v}}=$ $\operatorname{diag}(1.0,1.0)$, the weighting factor $s=0.2$, and the initial vehicle speed of $22 \mathrm{~m} / \mathrm{s}$, conduct 

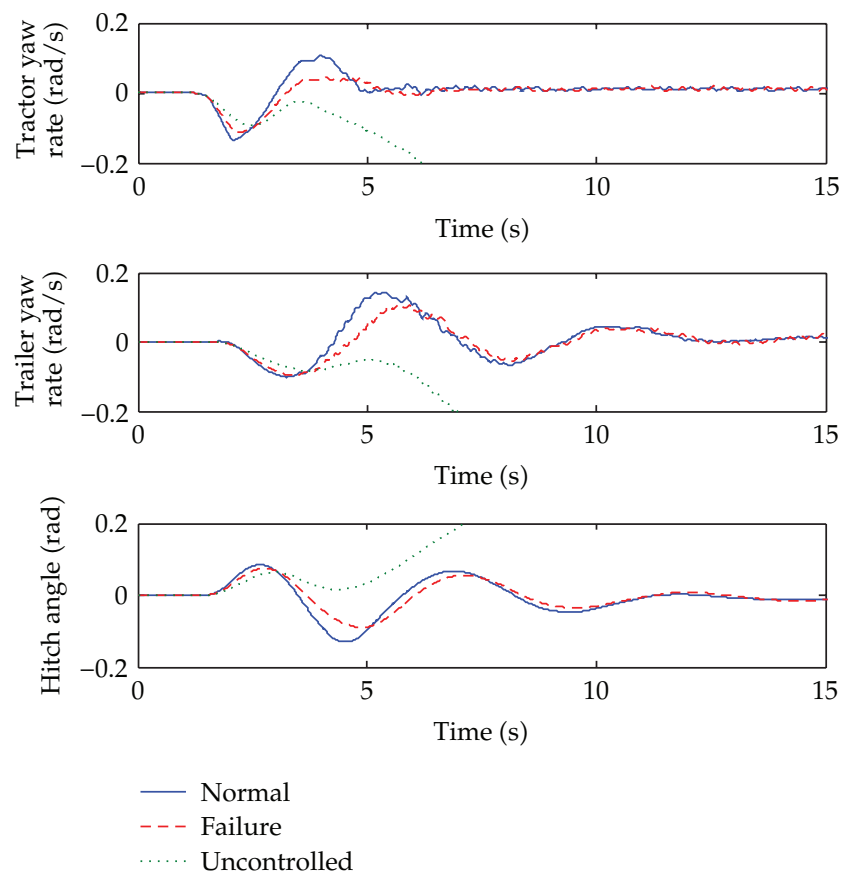

Figure 6: Yaw response comparison.

the single lane change maneuver simulation, respectively, in the three cases and the state response results are shown in Figures 6, 7, and 8 including the tractor and trailer yaw rate, slip angle, hitch angle and vehicle speed.

As given by the figures, in the normal control case with the proposed reconfigurable control scheme, the vehicle represents satisfying response performance with respect to the steer input except for a bit tractor side slip. Further, in the failure control case where the trailer brake actuators are completely fails and the tractor actuators are heavy partly fails, owing to the reconfigurable coordination of the remaining functioning actuators/efforts, the vehicle can still keep stable and can generally follow the steer input except for a bit decrement of response performance compared to the normal control case. However, in the uncontrolled case, the vehicle loses control rapidly. Due to the brake actuator damage, the brake force/torque for the failure case decreases considerably and the vehicle speed shall be relatively lightly affected compared to the normal case as illustrated by Figure 8 .

Figures 9 and 10 illustrated the estimations of the brake force limit of all wheels in the lane change maneuver. Brake force limit which is directly related to the vehicle handling attitude is estimated in real-time for the CWLS optimization based CA algorithm to determine the optimal brake force effort. Comparing the two cases, we can find that the difference of vehicle response leads to different brake force limit. With the estimated brake force limit, the optimized brake forces are obtained by solving the CA problem (3.27), and by multiplying the wheel radius the reconfigured optimal brake torques can be achieved and are illustrated in Figures 11 and 12, respectively, for the normal and failure case. It is obvious that the damaged but still functioning actuators $1-4$ are reconfigured optimally to realize the corrective yaw moment from the upper level SMYC as possible. Note that no brake effort has been assigned to the trailer wheels since the actuators of which are completely failed. 

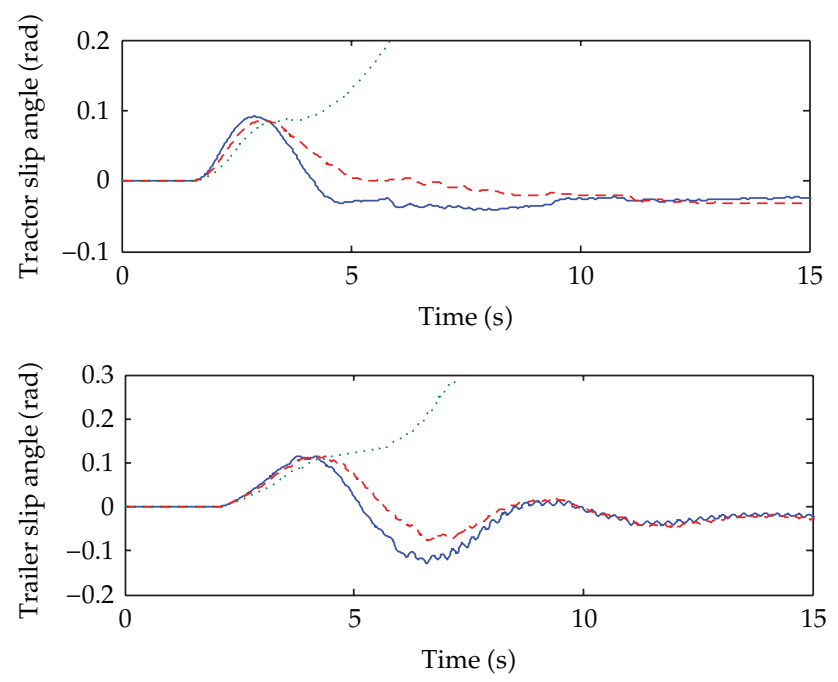

- Normal

- - - Failure

Uncontrolled

Figure 7: Side slip response comparison.

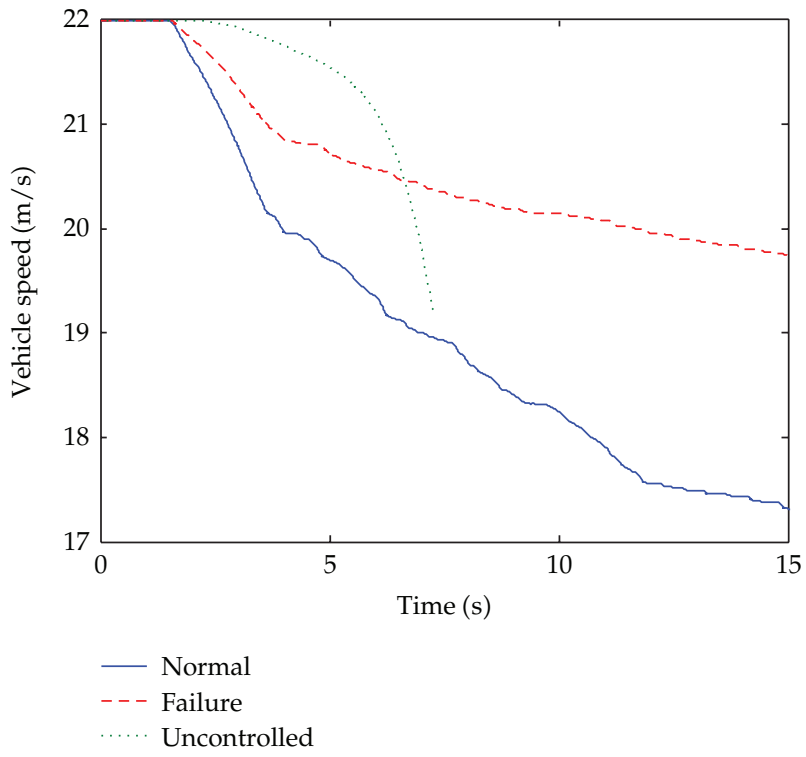

Figure 8: Vehicle speed response comparison.

Similarly, the difference in wheel longitudinal slip ratio can also be found as shown in Figures 13 and 14 which corresponds to the brake force. All slip ratios are below 0.2 without wheel locking for heavy brake. Figures 15 and 16, respectively, show the realization of the corrective yaw moment vector $\mathbf{v}=\Delta \mathbf{M}$ from the upper level SMYC for the normal and fail case. Since the reference corrective yaw moment $\Delta \mathbf{M}$ is calculated by sliding mode control 

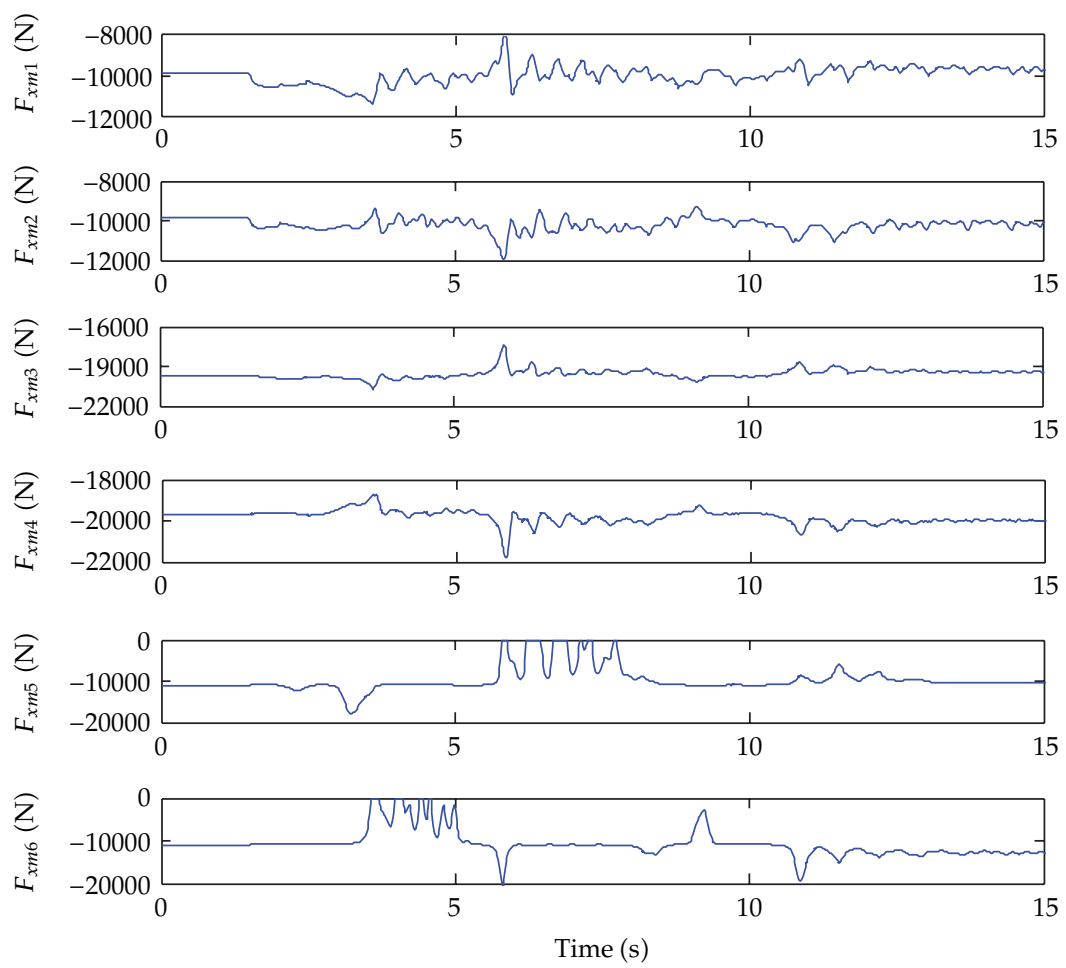

Figure 9: Brake force limit estimation in the normal control case.

to follow the reference response of the on board model, it does not mean that the corrective yaw moment can be realized completely by active wheel brake due to the physical limit of the brake force. So the actual produced corrective yaw moment presents a remarkable gap to the desired value from SMYC and this is much more remarkable for the failure control case due to the fail of actuator.

The above simulations and analysis reveal that reconfigurable control method based on CA technique is feasible to be used in the stability control system design of tractorsemitrailer double-body vehicle. Especially, the reconfigurable control system can still keep the vehicle stable in the situation of brake actuator being damaged greatly by reconfiguring the remaining functioning actuators/efforts and thereby the reliability and safety are improved compared with the conventional single wheel brake method.

\section{Conclusions}

In order to evaluate the proposed reconfigurable control scheme, a 14-DOF nonlinear model is constructed for a typical five-axle tractor-semitrailer vehicle which can generally reflect the actual vehicle dynamics especially in critical driving situations. A two-level structure reconfigurable control scheme is proposed with the upper level of SMYC and the lower level of yaw moment allocator based on CWLS optimization algorithm. As a particular feature of this control scheme, the brake force limit as one of the required conditions for the CWLS optimization generally varying with the handling maneuver is estimated in real time to improve the CA performance. The reconfigurable control issue based on CA technique is transformed to 

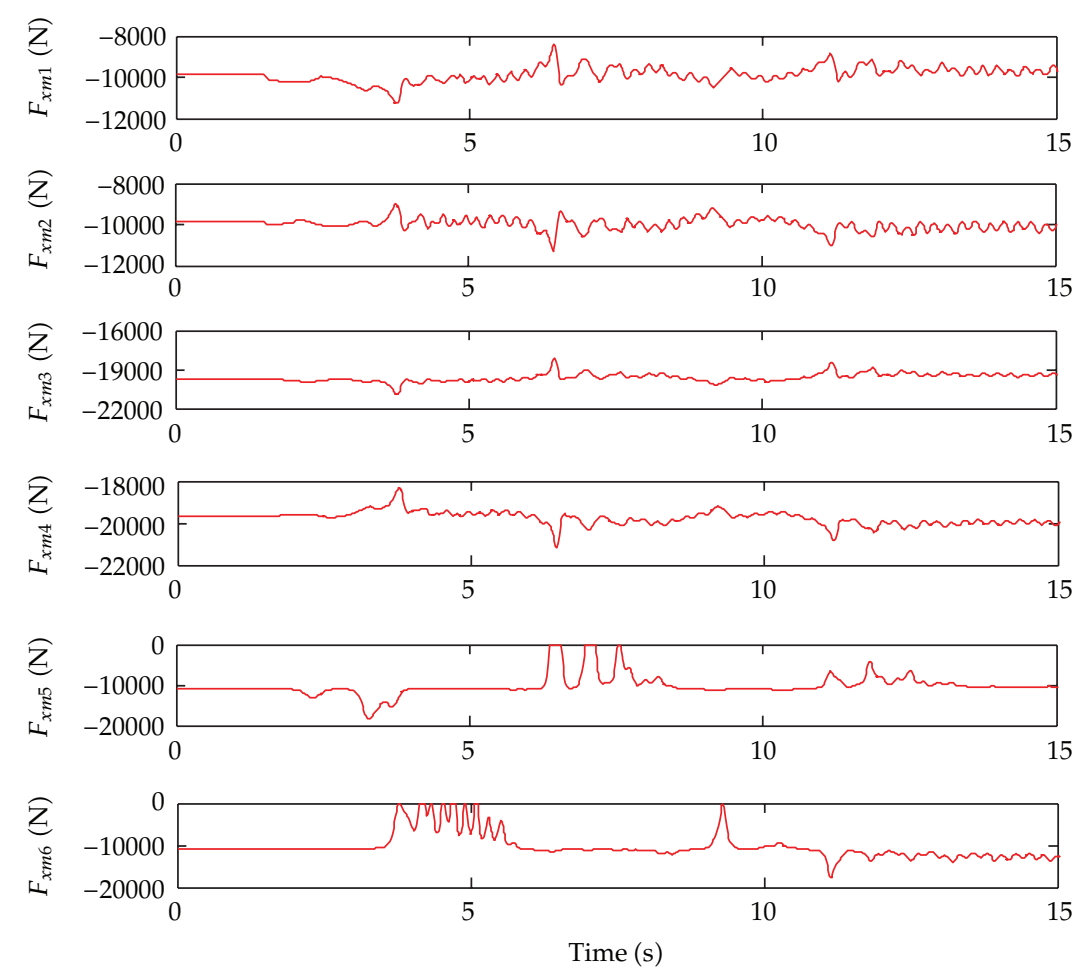

Figure 10: Brake force limit estimation in the failure control case.
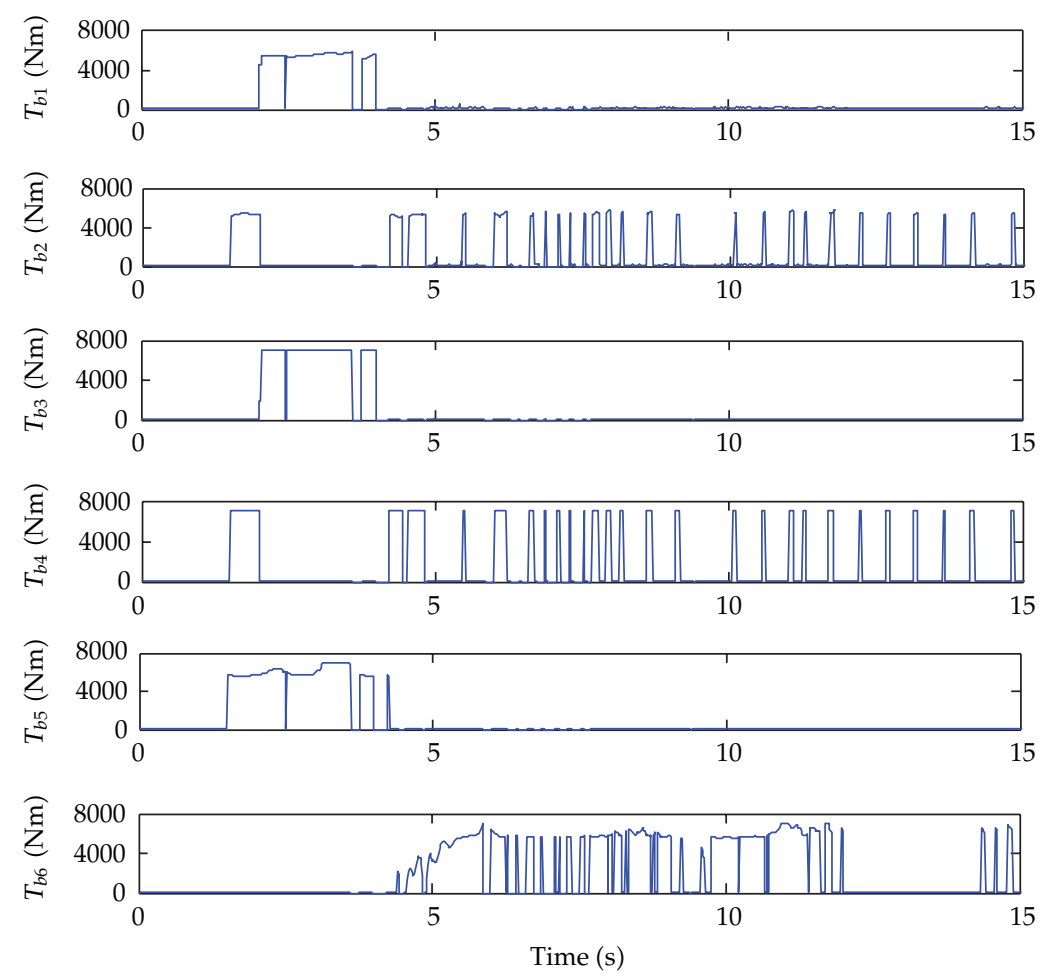

Figure 11: Brake torque effort for the normal control case. 

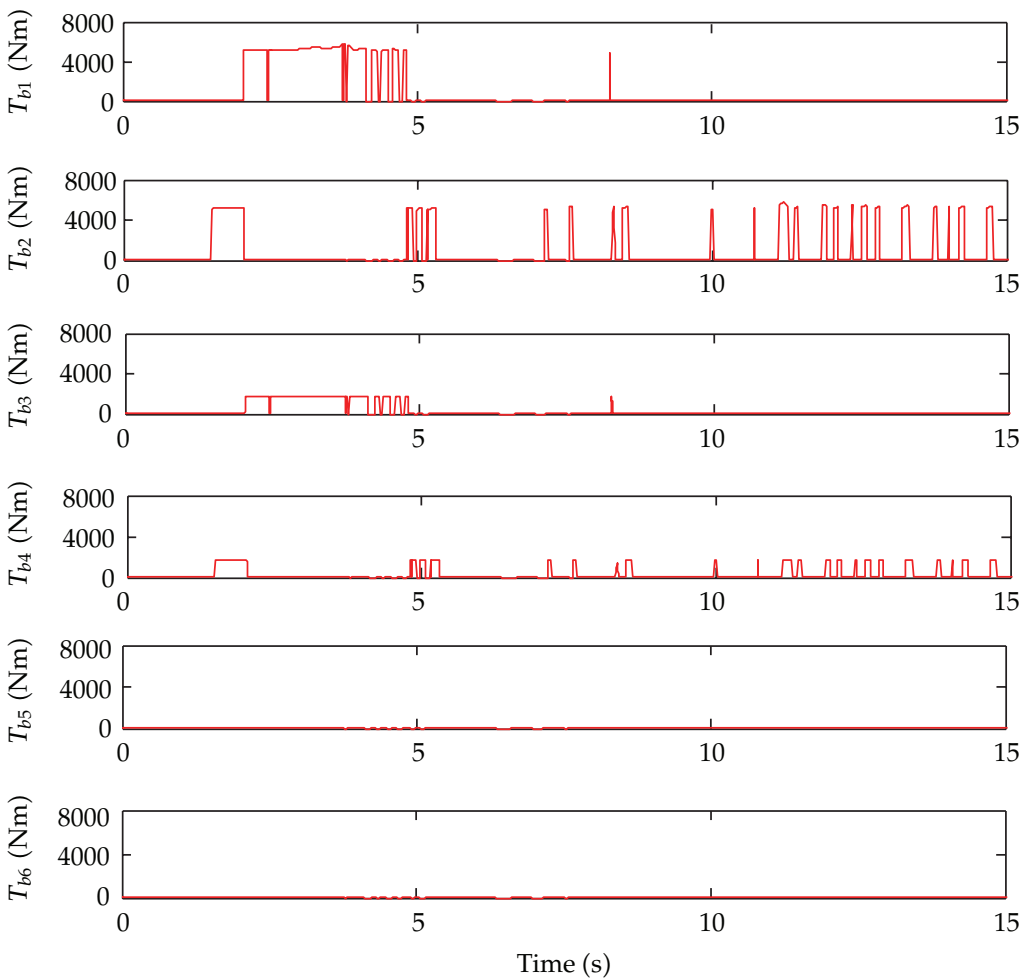

Figure 12: Brake torque effort for the failure control case.
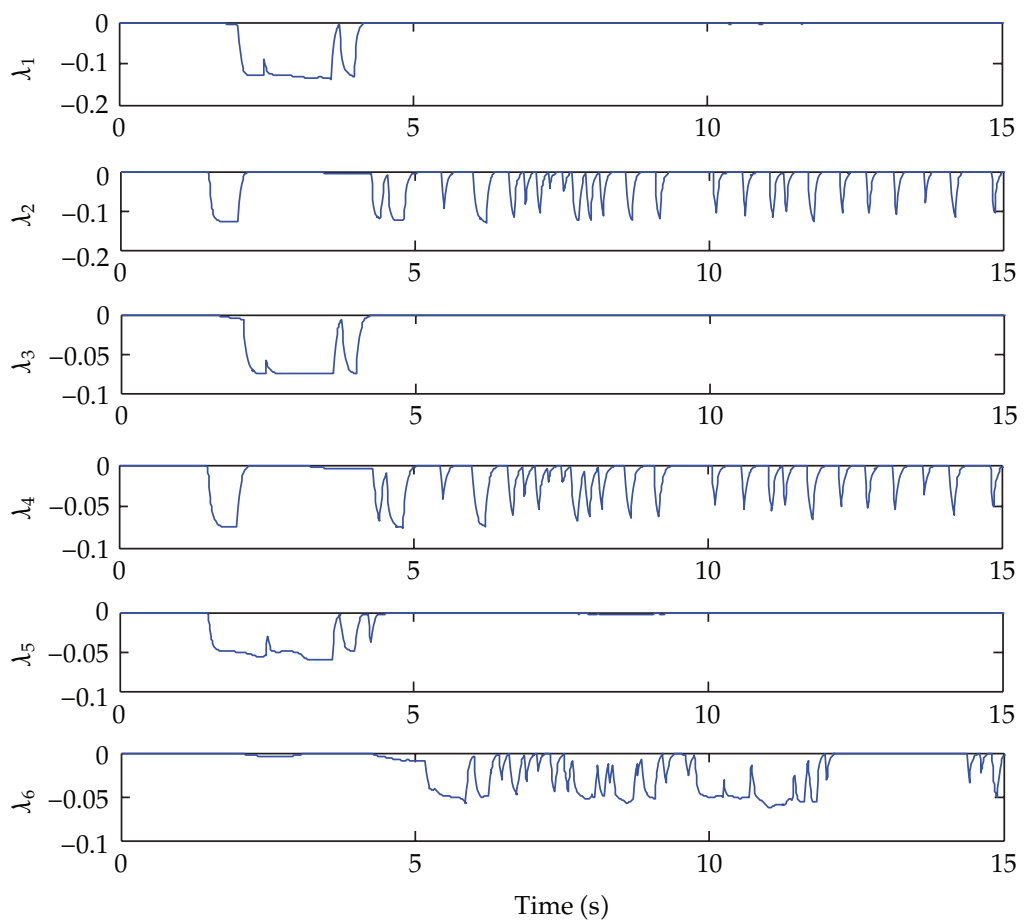

Figure 13: Longitudinal slip ratio in the normal control case. 

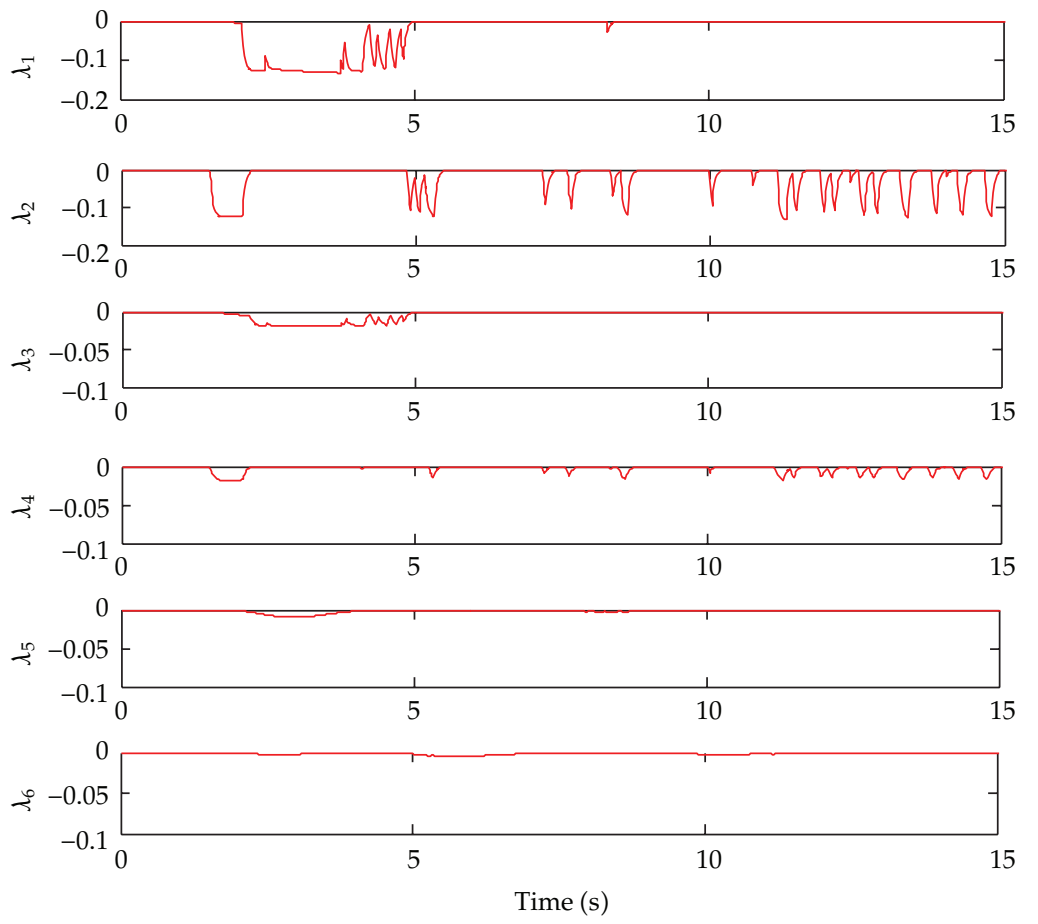

Figure 14: Longitudinal slip ratio in the failure control case.
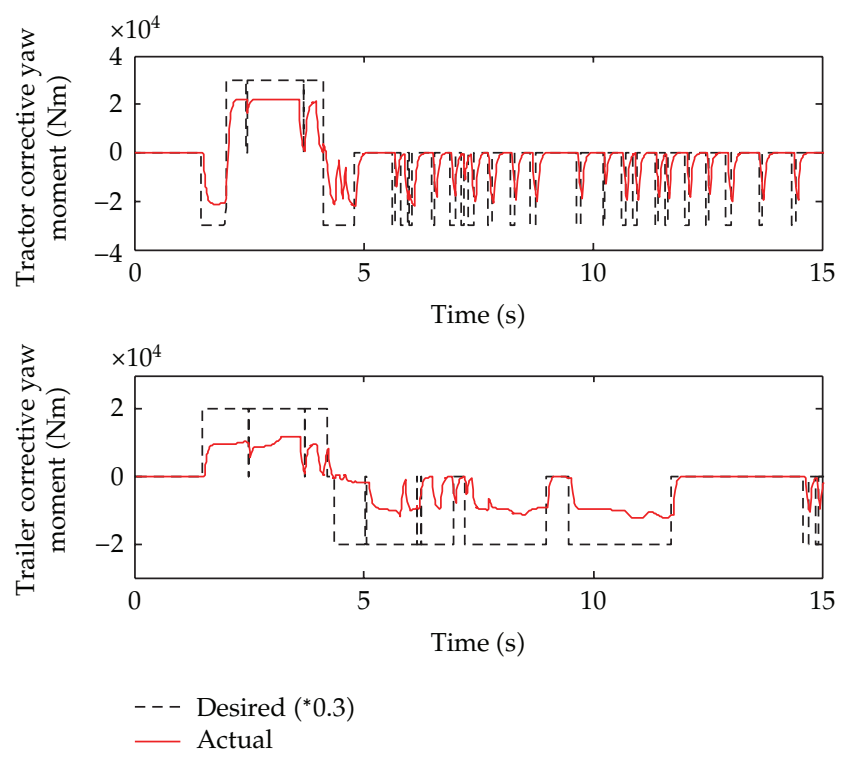

Figure 15: Corrective yaw moment in the normal control case.

a combination of error minimization and control minimization problem formulated by CWLS optimization and solved with AS algorithm. Simulations conducted on the 14-DOF nonlinear model reveal that the CA technique based reconfigurable control is rather significant for 

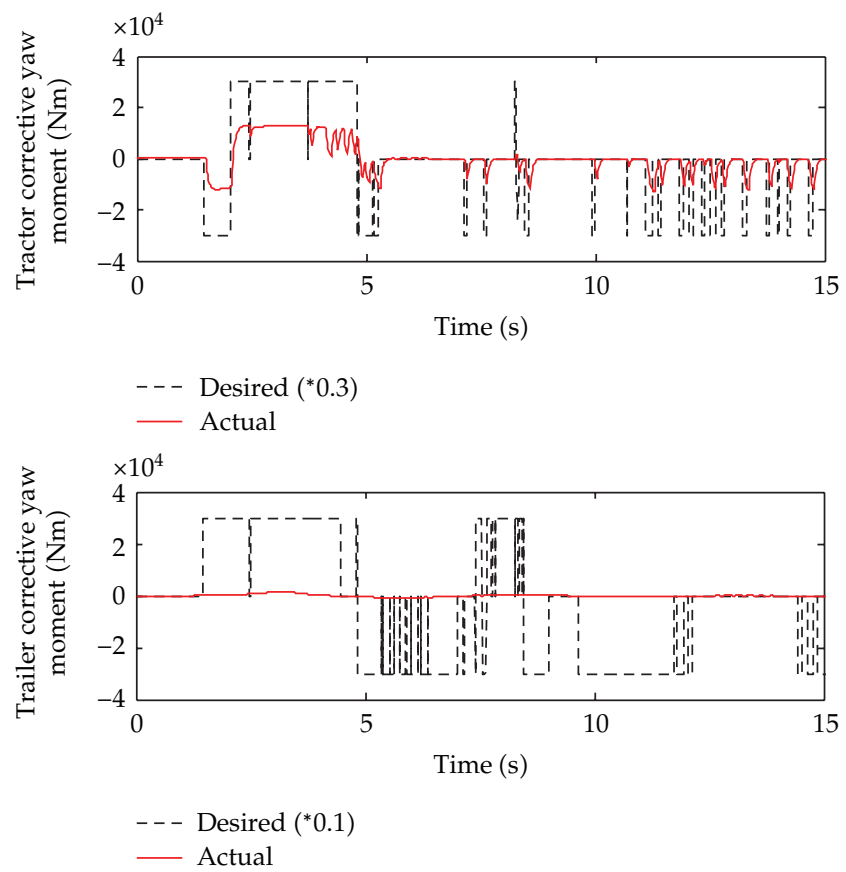

Figure 16: Brake force limit estimation in the failure control case.

the tractor-semitrailer vehicle since its multiple-axle structure can enrich the alternatives of possible actuator combinations in CA optimization.

\section{Acknowledgment}

This project was supported by the National Natural Science Foundation of China (no. 51005109). The authors are greatly thankful for the financial support.

\section{References}

[1] Y. He, A. Khajepour, J. McPhee, and X. Wang, "Dynamic modelling and stability analysis of articulated frame steer vehicles," International Journal of Heavy Vehicle Systems, vol. 12, no. 1, pp. 28-59, 2005.

[2] H. Aleksander, F. Daniel, and C. Hsien, "Stability and control considerations of vehicle-trailer combination," SAE Paper 2008-01-1228, SAE International, Warrendale, Pa, USA, 2008.

[3] M. A. Fernandez and R. Sharp, "Caravan active braking system-effective stabilisation of snaking of combination vehicles," SAE Paper 2001-01-3188, SAE International, Warrendale, Pa, USA, 2001.

[4] J. M. Williams and F. W. Mohn, "Trailer stabilization through active braking of the towing vehicle," SAE Paper 2004-01-1069, SAE International, Warrendale, Pa, USA, 2004.

[5] X. J. Yang, C. X. Yang, X. Zhang et al., "Yaw stability control for tractor-semitrailer combination based on active braking," Qi Che Gongcheng/Automotive Engineering, vol. 33, no. 11, pp. 955-961 (Chinese).

[6] K. Koibuchi, M. Yamaoto, Y. Fukada et al., "Vehicle stability control in limit cornering by active brake," SAE Paper 960487, SAE International, Warrendale, Pa, USA, 1996.

[7] M. Abe, Y. Kano, Y. Shibahata, and Y. Furukawa, "Improvement of vehicle handling safety with vehicle side-slip control by direct yaw moment," Vehicle System Dynamics, vol. 33, pp. 665-679, 2000.

[8] B. L. Boada, M. J. L. Boada, and V. Díaz, "Fuzzy-logic applied to yaw moment control for vehicle stability," Vehicle System Dynamics, vol. 43, no. 10, pp. 753-770, 2005. 
[9] X. Yang, Z. Wang, and W. Peng, "Coordinated control of AFS and DYC for vehicle handling and stability based on optimal guaranteed cost theory," Vehicle System Dynamics, vol. 47, no. 1, pp. 57-79, 2009.

[10] J. Wang and R. G. Longoria, "Coordinated and reconfigurable vehicle dynamics control," IEEE Transactions on Control Systems Technology, vol. 17, no. 3, pp. 723-732, 2009.

[11] E. B. Roger, Application of Control Allocation Methods to Linear Systems with Four or More Objectives [PhD dissertation], Virginia Polytechnic Institute and State University, Blacksburg, Va, USA, 2002.

[12] B. M. Min, E. T. Kim, and M. J. Tahk, "Application of control allocation methods to SAT-II UAV," in Proceedings of the AIAA Guidance, Navigation, and Control Conference, pp. 5651-5660, San Francisco, Calif, USA, August 2005.

[13] J. H. Plumlee, D. M. Bevly, and A. S. Hodel, "Control of a ground vehicle using quadratic programming based control allocation techniques," in Proceedings of the 2004 American Control Conference (AAC '04), pp. 4704-4709, Boston, Mass, USA, July 2004.

[14] K. Tagesson, P. Sundstrom, L. Laine, and N. Dela, "Real-time performance of control allocation for actuator coordination in heavy vehicles," in Proceedings of the IEEE Intelligent Vehicles Symposium, pp. 685-690, Xi'an, China, June 2009.

[15] SAE, "Manual on design and application of leaf springs," Tech. Rep. SAE HS J788, SAE International, Warrendale, Pa, USA, 1980.

[16] H. Dugoff, P. S. Francher, and L. Segel, "An analysis of tire traction properties and their influence on vehicle dynamic performance," SAE Paper 700377, SAE International, Warrendale, Pa, USA, 1970.

[17] M. Nagai, M. Shino, and F. Gao, "Study on integrated control of active front steer angle and direct yaw moment," JSAE Review, vol. 23, no. 3, pp. 309-315, 2002.

[18] R. Rajamani, Vehicle Dynamics and Control, Springer, New York, NY, USA, 2006.

[19] X. Yang, Y. Li, and J. Xiong, "Analysis on the lateral stability and instability mechanism of tractorsemitrailer combination," Qiche Gongcheng/Automotive Engineering, vol. 33, no. 6, pp. 486-492, 2011.

[20] Y. Fukada, "Slip-angle estimation for vehicle stability control," Vehicle System Dynamics, vol. 32, no. 4, pp. 375-388, 1999.

[21] D. Piyabongkarn, R. Rajamani, J. A. Grogg, and J. Y. Lew, “Development and experimental evaluation of a slip angle estimator for vehicle stability control," IEEE Transactions on Control Systems Technology, vol. 17, no. 1, pp. 78-88, 2009.

[22] H. B. Pacejka and E. A. Bakker, "New tire model with an application in vehicle dynamics studies," SAE Paper 890087, SAE International, Warrendale, Pa, USA, 1989.

[23] O. Harkegard, "Efficient active set algorithms for solving constrained least squares problems in aircraft control allocation," in Proceedings of the 41st IEEE Conference on Decision and Control, pp. 1295 1300, Las Vegas, Nev, USA, December 2002. 


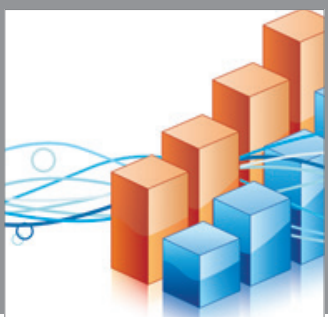

Advances in

Operations Research

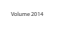

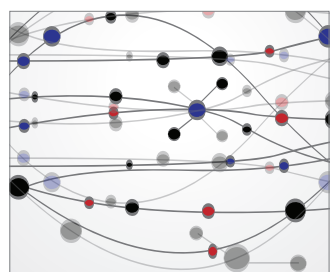

\section{The Scientific} World Journal
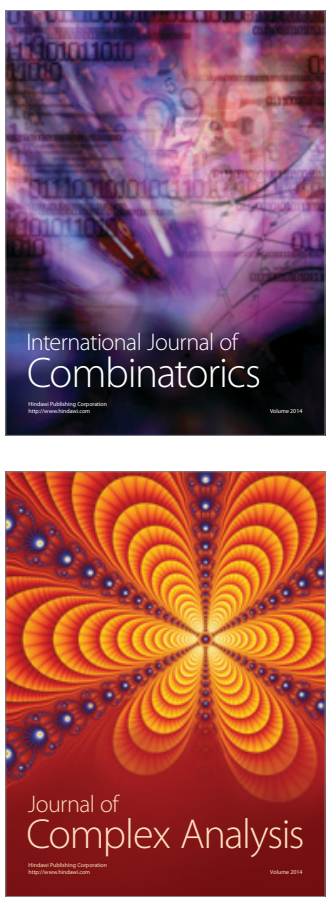

International Journal of

Mathematics and

Mathematical

Sciences
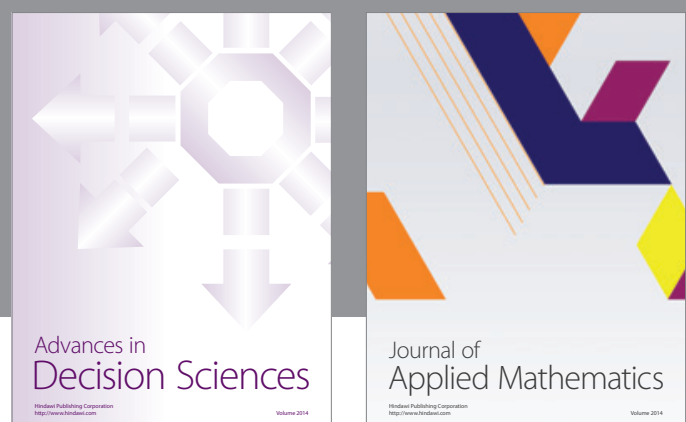

Journal of

Applied Mathematics
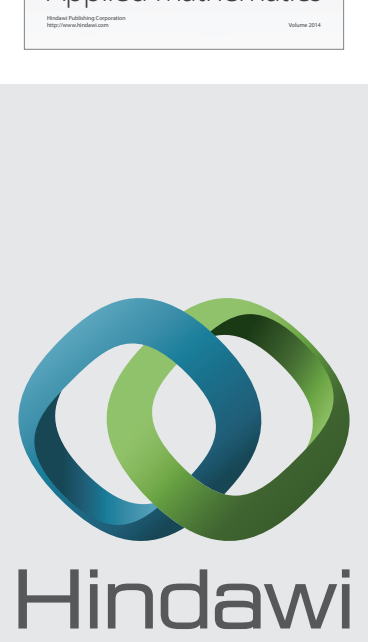

Submit your manuscripts at http://www.hindawi.com
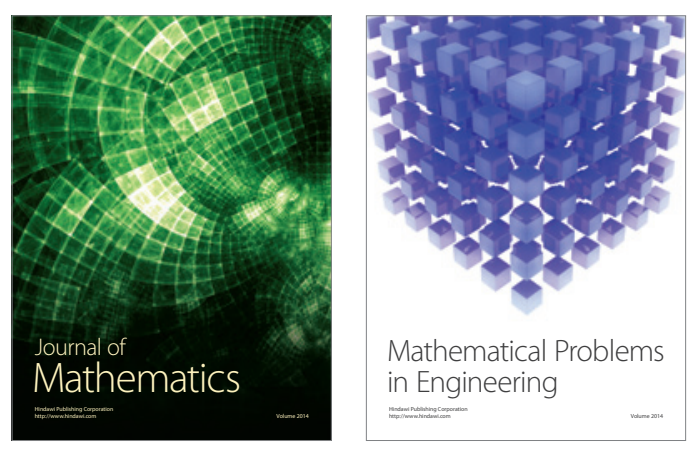

Mathematical Problems in Engineering
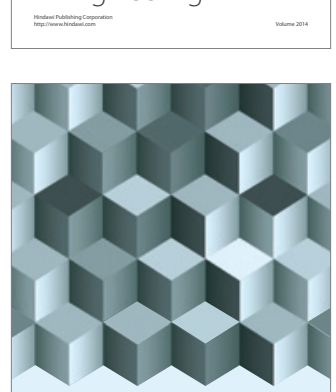

Journal of

Function Spaces
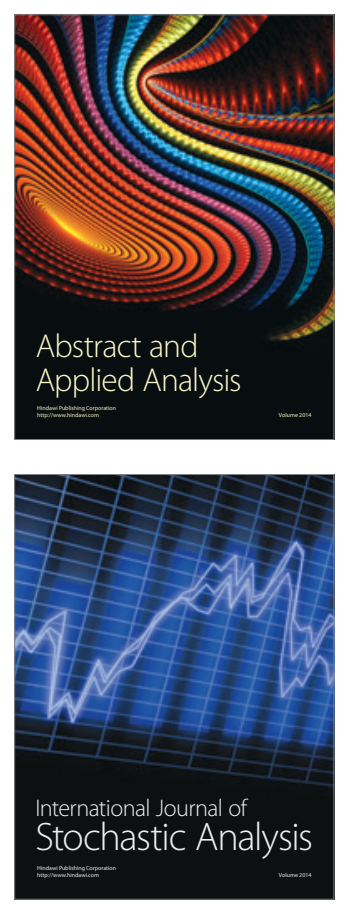

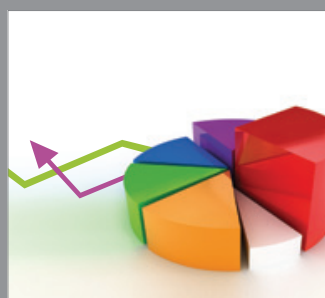

ournal of

Probability and Statistics

Promensencen
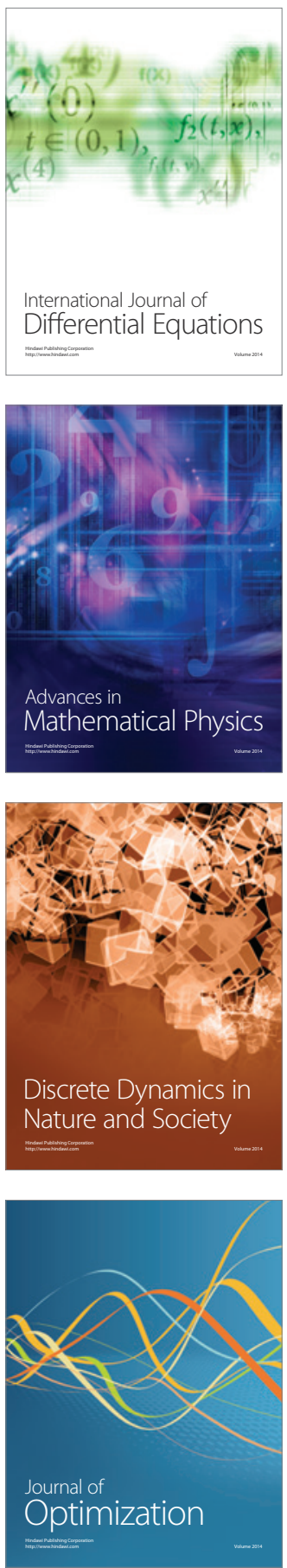